RECEIVED

DEC 051995

OSTI

POLLUTION PREVENTION

OPPORTUNITY ASSESSMENTS

GUIDANCE FOR THE HANFORD SITE

Westinghouse Hanford Pollution Prevention Group 


\section{LEGAL DISCLAIMER}

This report was prepared as an account of work sponsored by an agency of the United States Government. Neither the United States Government nor any agency thereof, nor any of their employees, nor any of their contractors, subcontractors or their employees, makes any warranty, express or implied, or assumes any legal liability or responsibility for the accuracy, completeness, or any third party's use or the results of such use of any information, apparatus, product, or process disclosed, or represents that its use would not infringe privately owned rights. Reference herein to any specilic commercial product, process, or service by trade name, trademark, manufacturer, or otherwise, does not necessarily constitute or imply its endorsement, recommendation, or favoring by the United States Government or any agency thereof or its contractors or subcontractors. The views and opinions of authors expressed herein do not necessarily state or reflect those of the United States Government or any agency thereof.

This report has been reproduced from the best available copy.

Printed in the United States of America

DISCLM-2.CHP (1-91) 
WHC-MR-0472

Rev. 0

\title{
Pollution Prevention Opportunity Assessments Guidance for the Hanford Site
}

\author{
J. A. Engel \\ Westinghouse Hanford Company \\ Date Published \\ October 1994
}

Westinghouse Hanford Pollution Prevention Group

P.O. Box 1970, B2-22

Richland, Washington 99352

Westinghouse Hanford Company is the Hanford Operations and Engineering

Contractor for the U.S. Department of Energy under Contract DE-AC06-87RL 10930

Approved for Public Release 


\section{DISCLAMMER}

Portions of this document may be illegible in electronic image products. Images are produced from the best available original document. 


\section{Table of Contents}

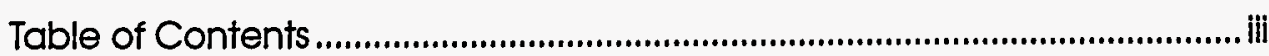

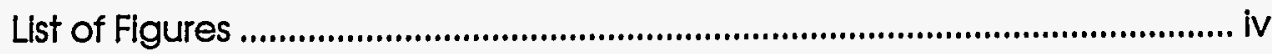

1.0 Introduction ("Why Do It?") .......................................................................... I

What is P2? What is a P2OA? ............................................................. I

Benefits of Pollution Prevention ................................................................. 3

Regulatory/Reporting Requirements ....................................................... 5

Why Another Guide ................................................................................... 5

2.0 How to Prioritize Your Waste Streams \& Activities ......................................... 7

Information Required \& Sources ........................................................... 7

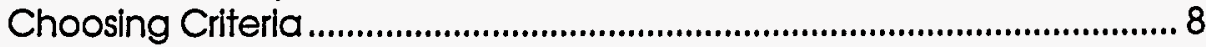

Picking Activities ...................................................................................... 9

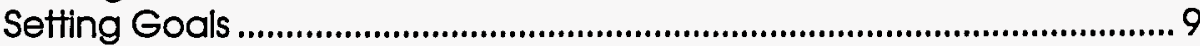

3.0 How to Conduct a P2OA .............................................................................. 11

Step 1: Build a Team .............................................................................. 11

Step 2: Learn About the Activity \& Gather Information ...................... 12

Step 3: Brainstorm ....................................................................................... 12

Step 4: Research Solutions ..................................................................... 13

Step 5: Prioritize Options \& Make Recommendations ......................... 14

Example P2OA: Spray Painting ............................................................... 15

4.0 How to Implement a P2 Opportunity .......................................................... 17

Suggested Approach ................................................................................ 17

Identifying Funding Sources ................................................................ 17

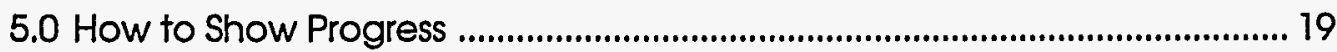

Tracking Techniques .............................................................................. 19

Getting Credit for Your Work -Who to Tell ................................................ 20

6.0 How to Deal with Special Problems (Troubleshooting) ................................ 23

Project-Oriented Activities .......................................................................... 23

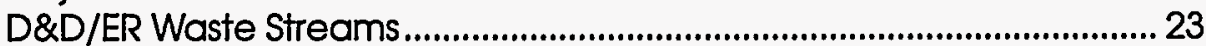

Facility Design/Modification ................................................................... 24

Laboratory Activities .......................................................................... 25

7.0 Conclusion ......................................................................................................... 27

Appendix A: Blank Worksheets

Appendix B: Spray Painting P2OA Example Worksheets

Appendix C: P2 Group Contacts and other Hanford Numbers

Appendix D: Off-Site Help and References 


\section{List of Figures}

Figure 1: Graphical Presentation of Pollution Prevention Concepts .............. 2

Figure 2: Graphical Presentation of Waste Management Methods................ 3

Figure 3: Pollution Prevention Procedure ......................................................... 4

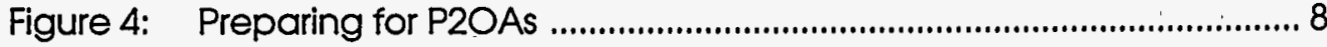

Figure 5: $\quad 5$ Steps for a P2OA ...................................................................... 11

Figure 6: Brainstorming Tool, Fishbone Diagram ......................................... 13

Figure 7: 4 Steps to Implement a P2 Opportunity ............................................ 17 


\section{POLLUTION PREVENTION OPPORTUNITY ASSESSMENTS: GUIDANCE FOR THE HANFORD SITE}

\subsection{Introduction ("Why Do It?")}

The purpose of this document is to provide help to you, Hanford waste generators, in finding ways to reduce waste through Pollution Prevention (P2) and Pollution Prevention Opportunity Assessments (P2OAs). It is based on guidance from other sites, and serves to compliment the Hanford-specific training on P2OAs offered by the Pollution Prevention group at Westinghouse Hanford Company (WHC).

The chapters of this document include help on how to choose major waste generating activities, how to conduct a P2OA, how to get results, and how to show progress. There is also a chapter on special situations and problems your facility may encounter. This first chapter tells you why you should consider conducting P2OAs and why they may be required.

\section{What is $P 2$ ? What is a $P 2 O A$ ?}

Pollution Prevention, or P2, may have been known to you as Waste Minimization. You may have also heard the terms Source Reduction, Recycling, and Treatment. These terms are related and are often used interchangeably. All five terms are part of a Pollution Prevention program, which at Hanford includes facility Pollution Prevention committees and a central Pollution Prevention Group managed by WHC.

A Pollution Prevention (P2) program can be defined as an organized, comprehensive, and continual effort to achieve three goals:

- Reduce hazardous, radioactive, mixed, and non-regulated wastes

- Conserve resources such as energy and water; and

- Prevent or minimize pollutant releases to all environmental media from all operations and site cleanup activities.

The concepts of a Pollution Prevention Program are shown graphically in Figure 1.

A hierarchical approach to environmental management is applied to all types of waste; i.e., some kinds of waste management are better than others. The program priorities in descending order are:

1. Source reduction
Remember:

Reducing waste at

the source and recycling are the top two priorities in any Pollution Prevention program. 


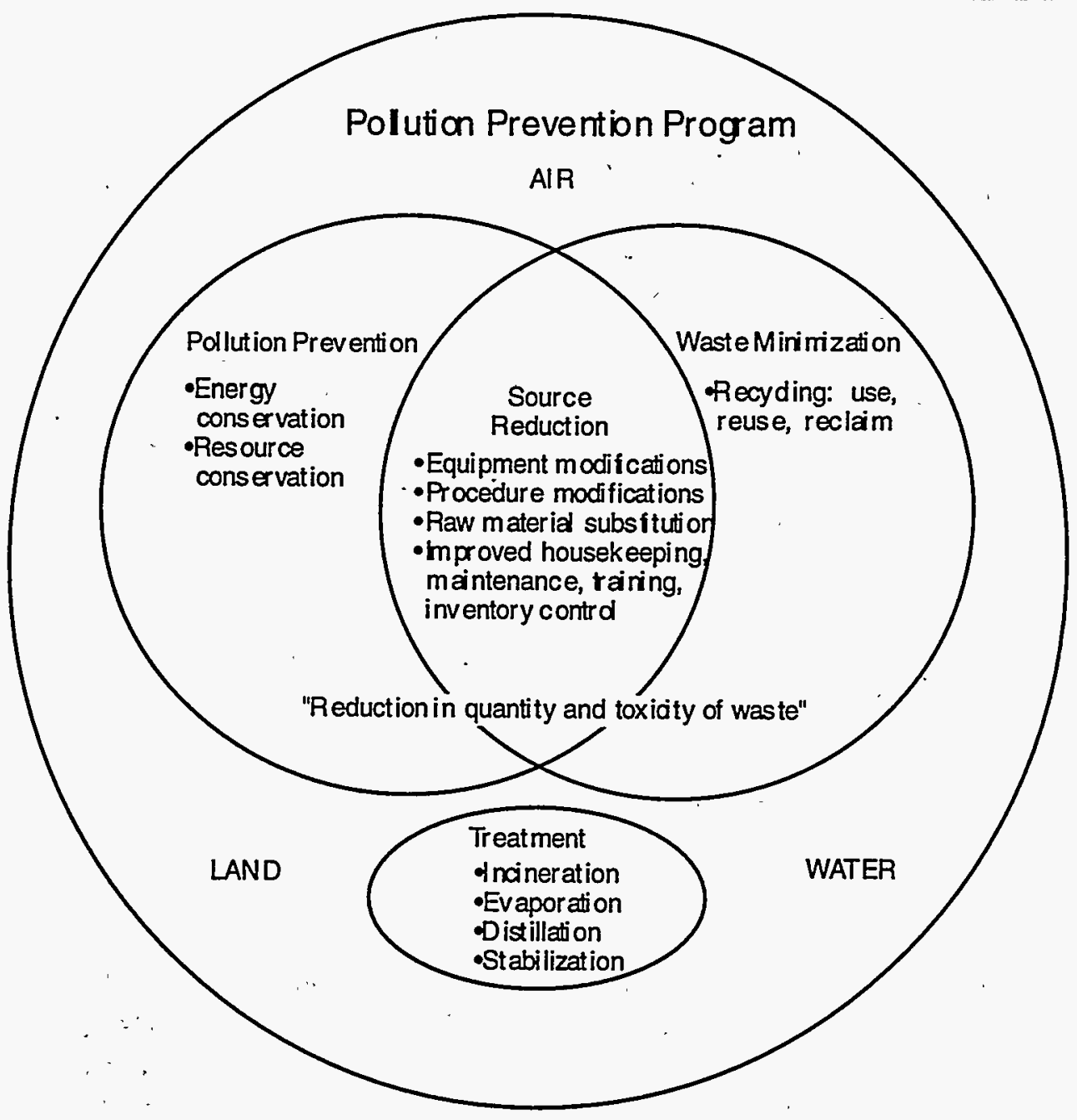

Figure 1:

Graphical Presentation of Pollution Prevention Concepts

2. Environmentally safe recycling

3. Waste treatment

4. Environmentally safe disposal.

Figure 1 lists examples of the first three kinds of waste management. A graphical representation of these strategies can be seen in Figure 2.

A systematic way of finding methods to reduce waste is through a Pollution Prevention Opportunity Assessment, or a P2OA. AP2OA is conducted by a select team that identifies and prioritizes waste streams, examines the processes that cause the generation of the waste, and discovers ways to reduce this waste. Most P2OA programs begin with management commitment as well as the identification and prioritization of waste streams on which to focus. Conducting a P2OA consists of selecting a team, gathering information about the waste generating activity, brainstorming pollution prevention opportunities, researching those opportunities, and making recommendations. 
A good P2 program should also have a method to move from the $\mathrm{P} 2 \mathrm{OA}$ process to implementation of $\mathrm{P} 2$ opportunities. P2OAs are considered the standard method to identify and rank pollution prevention opportunities. They are used and recommended by the Environmental Protection Agency (EPA), the Department of Energy (DOE), private industry, and other state and federal regulatory agencies.

Figure 3 shows the steps for implementing.P2 opportunities and reducing waste. The shaded areas show the steps of a P2OA, revealing them as an integral part of implementing P2.

\section{Benefits of Pollution Prevention}

The benefits of pollution prevention include advantages to employees, the environment, and Hanford contractors. From a worker's safety point of view, $\mathrm{P} 2$ reduces personal exposure to chemicals and radioactivity, reduces the potential for serious accidents and spills, and reduces regulatory workload. As Low As Reasonably Achievable (ALARA) programs actively support pollution prevention efforts.

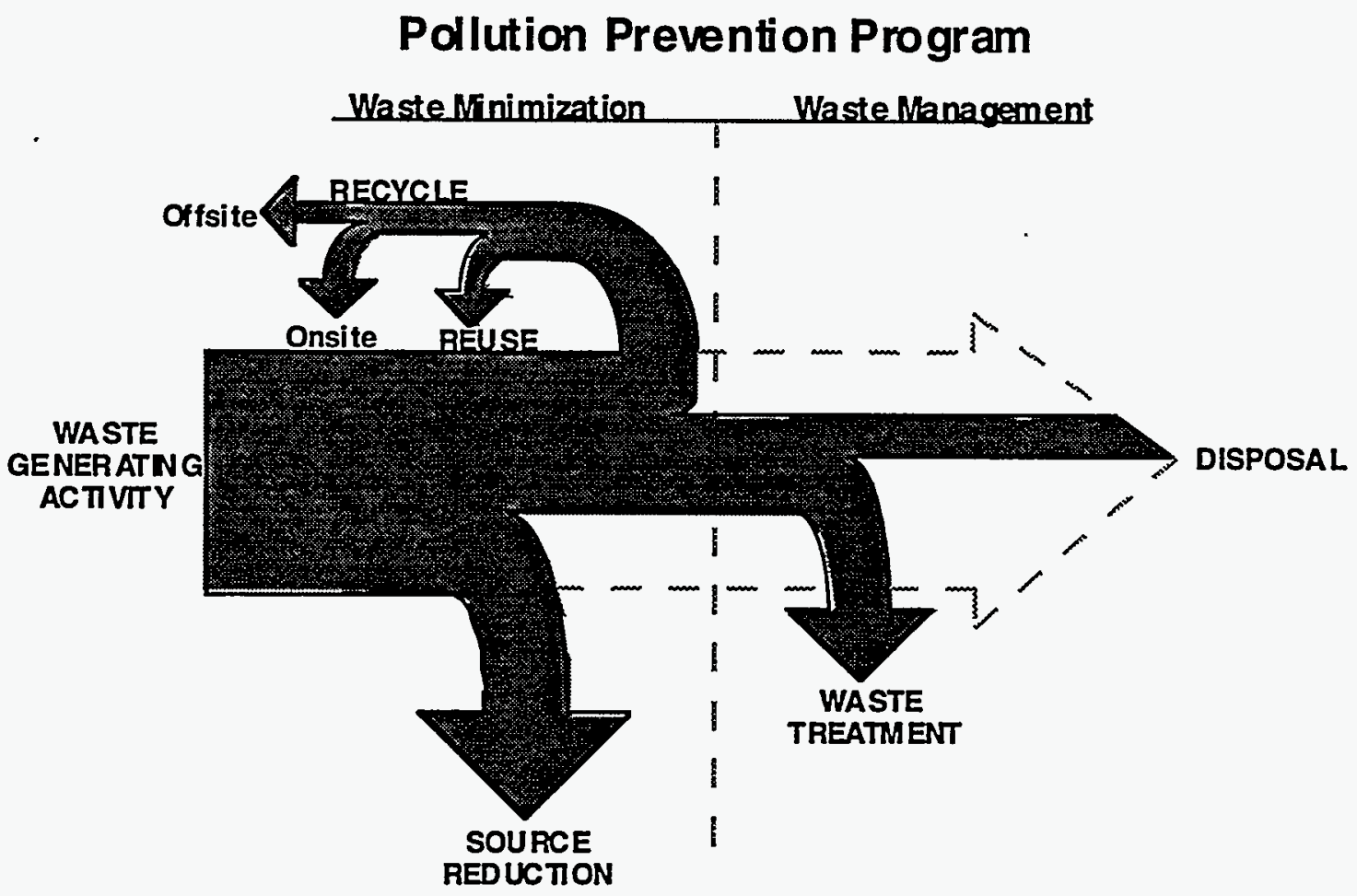

Figure 2:

Graphical Presentation of Waste Management Methods 


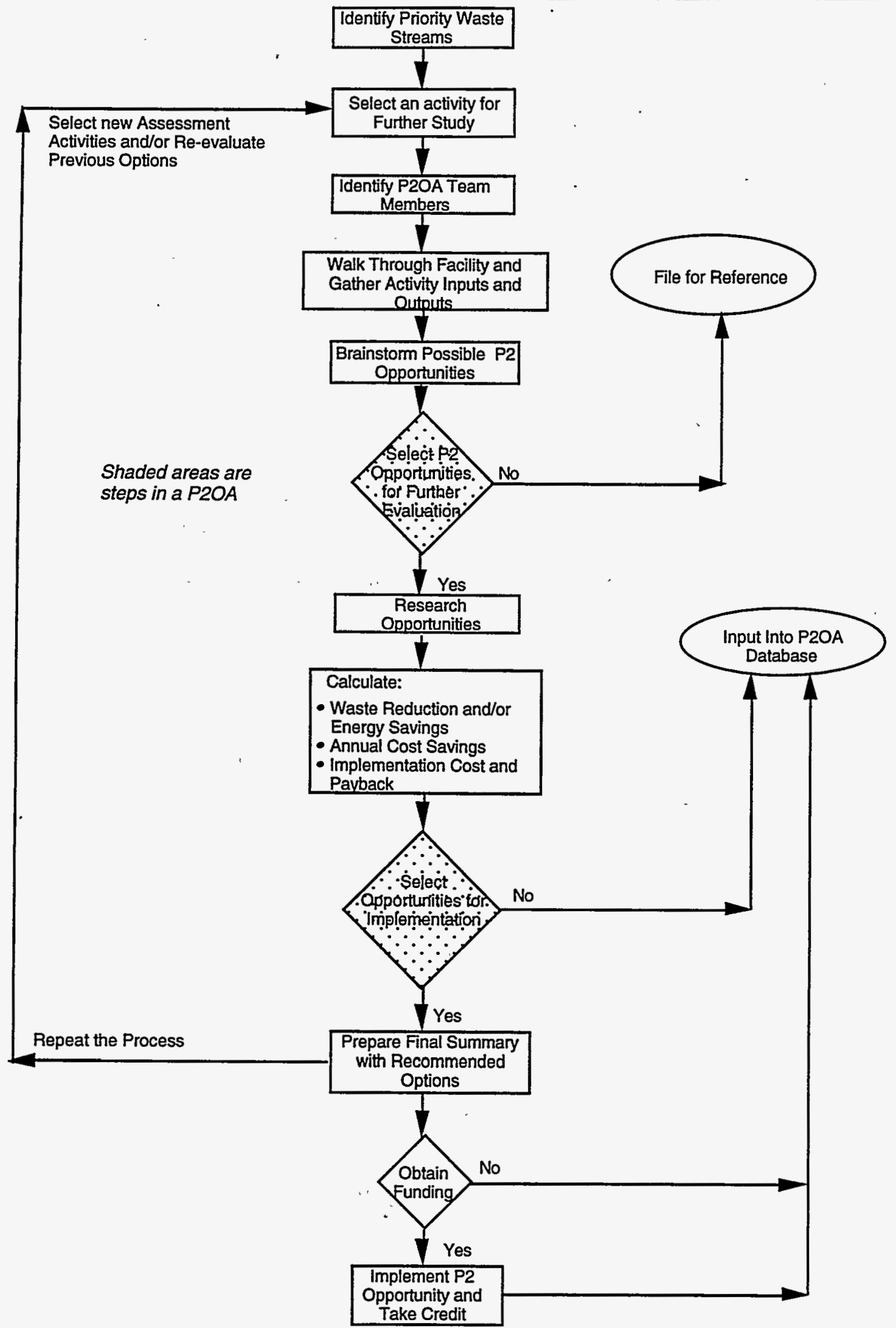

Figure 3:

Pollution Prevention Procedure 
The environmental benefits arise from the reduction of releases to the ground, water and air, and from conservation of resources such as raw materials, energy, and water. This protects both wildlife and the people of the area who all use the natural resources in order to live.

Finally, contractors, such as WHC, benefit from the reduction in compliance and reporting costs, improved efficiency of operations, improved public relations, and reduction of long term civil and criminal liability. P2 and P2OAs also foster a positive working relationship with regulators and with the community, as they are seen as positive technical and procedural activities.

Thus, P2 ensures worker safety, reduces damage to the environment, and saves money!

\section{Regulatory/Reporting Requirements}

Many regulatory requirements exist for pollution prevention. Several RCRA codes, DOE Order 5400.1, as well as Chapter 173-307 of the Washington Administrative Code (WAC 173-307), all require a Pollution Prevention/Waste Minimization Program Plan in place at each site-originally, in Hanford's case, at each facility. Currently, the Pollution Prevention Group has prepared a single Hanford Site Plan. Documentation of P2OAs and goals for those P2OAs are the regulatory requirements for each facility.

- This interpretation, which has been accepted by the State of Washington, is upheld by RCRA in the Implementation Guidance for DOE Order 5400.1, which specifies that "[t]he basic elements of an effective waste minimization program" include "periodic waste minimization assessments/audits." The order defines these assessments as "a continuing effort," not a "one time endeavor."

A guiding document from DOE, the Waste Minimization/Pollution Prevention Crosscut Plan 1994, offers some focus. This document strongly emphasizes cost effectiveness and rapid return on investment from the opportunities found with P2OAs. The Crosscut Plan focuses on all wastes types, as well as conservation of water and energy, as aspects of pollution prevention.

\section{Why Another Guide}

While EPA and other sites have issued guidance documents of various sizes and complexities in the past, Hanford's situation is unique enough that this Hanford-specific Guidance was developed, building on what other sites have accomplished.
Your regulatory responsibility is to set goals and conduct P2OAs, then submit them to the P2 group. They'll compile it and send it on to the regulators. 
Many factors affect how a P2OA is to be conducted, including size of the facility or site, number of waste streams, types of waste created, consistency of operations, and resources available. The Hanford site contains 1,450 square kilometers ( 560 square miles) of land, over 32 facilities, almost 200 hundred onsite and offsite waste generators, and thousands of waste sources. Additionally, Hanford's current mission of environmental restoration causes many operations to be discontinuous and project oriented, unlike a production facility.

This Guidance attempts to provide a method of prioritizing and assessing the volume and uniqueness of waste streams in a manageable fashion. Generally, this Guidance explains where to begin (by prioritizing waste streams), then how to conduct a P2OA, how to get a P2 initiative implemented, how to show progress, and how to deal with special problems such as nonroutine waste streams. The appendices include resources in completing a P2OA, as well as where to get help.

The key to remember is that the suggested methods in this Guidance are meant to be flexible and adaptable to Hanford generator situations and needs. Nothing is set in stone and the worksheets and methods can and should be adapted to situations, waste streams, facilities, and personalities, as long as they are working toward the common goal of seeking methods to reduce pollution of all kinds. Creativity and ingenuity in meeting the above objectives will always be encouraged.

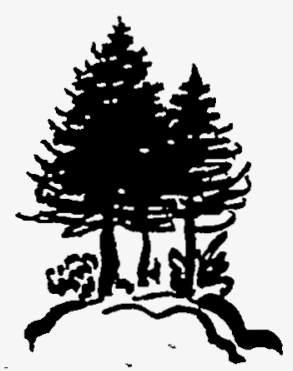


Before conducting P2OAs, first you must decide with which waste streams to begin. Since the number of waste streams at Hanford and any one of its facilities could number in the tens of thousands, it is important to group them together by common content or source and to prioritize them according to importance. This section describes where at Hanford to obtain information about waste streams, how to prioritize and.how to set reasonable goals in terms of the number of P2OAs to be done annually. The steps are also listed in Figure 4.

Review the waste stream and activity priorities on an annual basis. This way, information from the previous calendar or fiscal year can be used. Additionally, this will correspond with the reporting requirements of calendar year annual goals.

\section{Information Required \& Sources}

First, develop a material procurement list that identifies the hazardous products and chemicals purchased and used in your facility. Possible sources are facility chemical tracking inventories, the Hazardous Materials Inventory Database 2 (HMID2), or procurement records. These will be the major hazardous materials entering facility operations. Additionally, try to identify other sources of materials (hazardous, radioactive, nonregulated) entering the facility that end up creating or being handled as waste.

Your final input list should include, for example:

- Purchased materials of any significant quantity

- All purchased hazardous chemicals or materials

- Environmental samples received from onsite and offsite customers

- Material brought in by subcontractors or other persons

- Waste from customers to be treated, handled or disposed by your facility

- Legacy waste

This list must be general and should include any large material inputs or products of significant quantity coming in that become waste that you are ultimately responsible for. Modifying some of the activities generating these input streams may be out of your control, while others may be changeable-do not worry about that right now, those will be identified when doing a P2OA. 
Remember: Every year, review your waste streams and activities and set goals!

Blank Worksheets can be found in Appendix $A$
Next, determine waste streams and their quantities exiting your facility, including air emissions and water waste. This is done by looking at your material inputs and determining where those exit your facility. Possible sources for this information are the Solid Waste Information Tracking System (SWITS) database, satellite accumulation records, and waste manifests. These are the waste outputs from your activities. It is also beneficial to categorize these wastes by hazardous, radioactive, mixed, and sanitary (nonregulated), as it helps focus on what wastes are generated at your facility. Group these waste streams into large but practical categories. Also, determine from your waste generation numbers where your largest waste type is, such as LLW or HAZ - you may want to address those streams in particular.

\section{Choosing Criteria}

The data collected in the above section can now be summarized and criteria for prioritizing waste streams chosen. First, list the waste streams collected above on the "Waste Stream Information" worksheet [see Appendix A]. You may not want to list all the waste streams; one method is to choose the top 3 waste streams from each waste type. Or,you may want to focus entirely on a particular waste type (and its waste streams) that is a very high priority.

From this list, determine the mass of each waste stream and record that value on the worksheet. Mass and cost are two criteria that should be used to prioritize waste streams. These two values should be multiplied to calculate a total cost for generating the total quantity of waste. The costs per kilogram are on the back of the worksheet and are based on disposal costs charged to the generator at the Hanford Site. ( These cost values are not life cycle costs and are meant for prioritization only. When calculating cost savings later, you will want to include other, hidden costs, such as equipment, employee time, and others.)

\section{Figure 4: Preparing for P2OAS}

Get list of major chemical, radioactive and other material inputs

Get waste stream information

Determine volume and cost of each waste stream

Choose other important criteria

Rank your waste streams

List your main contributing activities

Set your goals

Go do your P2OAs!

Use the "Waste Stream Information" worksheet \& "Priority Streams and Activities" worksheet to guide your preparation 
You may want to use additional criteria to prioritize your waste. The "Other Concerns" column is where you would list any other important criteria besides cost and volume. These should be very specific to your facility. Perhaps a waste stream is a particular ALARA or safety hazard due to the way it must be handled. Or, it is very toxic to humans or the environment. Or, it is a waste stream that is very high profile with the community. All nonquantifiable but important criteria should be listed in the last column of Waste Stream Information worksheet.

Using data recorded from the first worksheet, now prioritize these waste streams. Generally, the stream with the highest total cost will be the highest priority waste stream. You may rank them strictly on cost and quantity (using the highest total cost as the highest priority), but you may also want to move streams up the priority list depending on their toxicity or other less quantifiable criteria recorded in the Other Concerns column. Record the top waste streams in order on the Priority Streams and Activities worksheet.

\section{Picking Activities}

Once the top streams are listed, it is time to determine what activities create these waste streams. These activities will be the ones on which you will conduct P2OAs. To prevent becoming overwhelmed, only list the top one to three waste generating activities for each waste stream. These activities will come from general knowledge of your facility and can be very broad (such as, "painting" or "sampling analysis"). Several activities may generate one waste stream. Group these activities when you can, otherwise consider them separate P2OAs. Once you have listed your activities, begin conducting your $\mathrm{P} 2 \mathrm{OAs}$.

Remember, the key to selecting P2OA activities is to identify actions in your facility that generate the most expensive and largest amount of waste. Once these are determined, the P2OA will look at all the waste streams from these activities (even though one stream may be a priority over others).

\section{Setting Goals}

Goals are required for the Hanford Site Pollution Prevention Program Plan. They are annual goals and are based on a calendar year. These goals should designate: how many P2OAs you plan to conduct in a year; how much waste you will minimize with P2OAs (percentage of total generated by your facility); and estimated reductions in toxic and hazardous chemicals purchased and used. This will de-
All the worksheets have instructions on the back! 
pend primarily on your resources. Remember, a P2OA does not include implementation of any opportunities, just the identification and recommendation of solutions [see Figure 3]. Guidance on goal setting can be received from the Pollution Prevention Group. 


\subsection{How to Conduct a P2OA}

Now that the priority waste generating activities are identified, the team is ready to begin a P2OA on each of the priority activities. A $\mathrm{P} 2 \mathrm{OA}$ is the primary mechanism used for identifying and analyzing activities for $\mathrm{P} 2$ opportunities, and provides the basis for developing and prioritizing P2 options.

A $22 \mathrm{OA}$ is an organized effort to identify ways to reduce or eliminate the priority waste stream. Potential pollution prevention opportunities are identified, evaluated, and prioritized according to environmental, health, safety, and economic criteria. Once pollution prevention opportunities are identified, schedules are developed and the opportunities are implemented.

The Hanford P2OA is broken down into five elements, which are described in detail in the next five sections. Each of these elements documents an important part of the P2OA activity. They also roughly correspond to the five worksheets that are provided in this Guidance. Blank worksheets can be found in Appendix A. Appendix B contains the worksheets for the P2OA described in the box on page 15.

\section{Figure 5: 5 Steps for a $\mathrm{P} 2 \mathrm{OA}$}

1. Build a team

2. Learn about the waste generating activity

3. Brainstorm ideas to reduce waste

4. Research those ideas for cost and feasibility

5. Prioritize options, make recommendations and plan to implement

Use Worksheets \#7-5 to help guide your P2OAs

\section{Step 1: Build a Team}

The first step should be building a team that will conduct each $\mathrm{P} 2 \mathrm{OA}$. The team usually includes a team leader who has technical and practical knowledge of the activity. This person is responsible for seeing that their P2OA worksheets are completed, opportunities are identified, and cost-effective opportunities are implemented.

In addition to the team leader, several other core members will assist in conducting the P2OA. These individuals can be people who know about the priority waste generating activity, or they can be unfamiliar to the specifics. Either way, the key is talking to the operators who do the waste generating activity and seeking out the technical information required from people who may not be part of the 
team. Team members or information sources should be selected based on their process knowledge, purchasing and material inventory knowledge, regulatory experience, or P2OA expertise and interest. Teams may vary in size depending on the nature of the activity.

Once a team has been organized, the P2OA leader can initiate the P2OA on the priority activity. The team members are recorded on Worksheet \#1.

\section{Step 2: Learn about the Activity \& Gather Information}

The first step the team will want to take is to get a hands-on feel for the activity they will be assessing. A tour of the area where the waste is generated is usually the most helpful. Talk with the operators since they are the most knowledgeable of the waste stream. Ask how they think the waste could be reduced; often they will have thought of P2 initiatives that they have not been able to implement. Watch how the work in completed to see if there are inefficiencies.

Other sources of information can be the material used and waste generated data collected previously, purchase requisitions, and examination of material and waste-containers.

In order to record this information, a narrative of the activity can be recorded on Worksheet \#1. Then, Worksheet \#2 can be used to map out the materials in and the wastes out of the activity. If this worksheet is too restrictive, feel free to complete one in a more freeform manner.

\section{Step 3: Brainstorm}

From a knowledge of the activity, the team can begin to seek out ideas to reduce waste. Brainstorming as a group is the best method for obtaining ideas, with the group including the team and any others who are directly involved with the activity. Try not to be negative as you brainstorm; the ideas do not have to be specific at this point; as an example, an idea to reduce solvent waste could be "Look for ways to recycle/reuse solvent." Amore detailed understanding of how to accomplish this comes during the next step. Figure 6 (and Appendix A) shows a tool that may help in brainstorming, a fishbone diagram. Record all ideas in some form for documentation.

Once a list of ideas is generated, the team can determine which ideas to pursue and assign those to interested team members. 


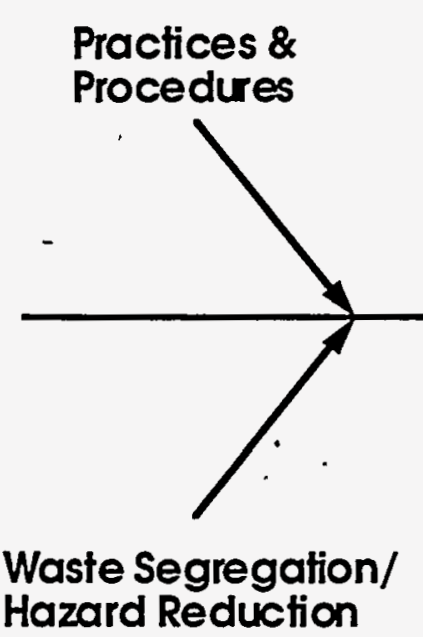
Hazard Reduction

\section{Material}

Substitution

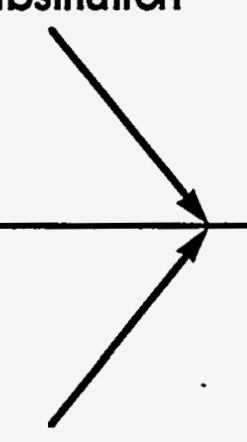

Recycling, Reuse

\& Reclamation

Figure 6:

Brainstorming Tool, Fishbone Diagram
Equipment

Modification

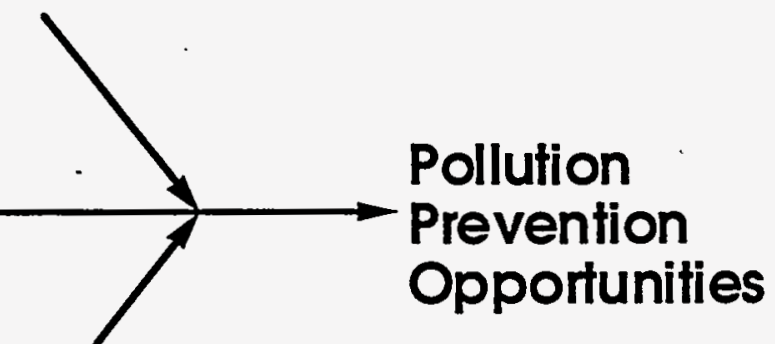

Step 4: Research Solutions

Each idea chosen will be developed and detailed on Worksheet \#3. One team member can be assigned to work on one opportunity or several. The opportunity should clearly define the current practice and then the assigned team member should seek out solutions. Sources of information could be vendors, the Pollution Prevention Group, EPA documents, or other facilities. These and other sources can be found in more detail in Appendices $C$ and $D$. A specific vendor does not have to be chosen; rather, information such as efficiency or cost of a particular technology can average the results from several vendors.

The results of the research should accomplish the following:

- Estimate Feasibility (Is there technology to accomplish what is desired and what is it?)

- Estimate Waste Reduction (How much and what kind of waste will be reduced, and is it a onetime reduction or annual? Are there any energy savings?)

- Estimate Cost Savings \& Payback (How much money will be saved from this initiative, how much will it cost to implement, and how long will it take to pay back?)

- Estimate Hazard Reduction \& Other Benefits (What other benefits, besides cost savings, such as increased safety, reduced toxicity, or regulatory relief, will be achieved with this initiative?)

For each P2OA, you will have one each of worksheets \#7, 2 , 4, \& 5. You will have many worksheets $\# 3$, one for each opportunity. 
Note: The 5 worksheets or equivalent make an excellent package to show progress to management and to seek out support!
When the research on each opportunity has been completed, the data can be recorded in detail on Worksheet \#3. There will be multiple Worksheets \#3, one for each initiative. Then, as a team, the opportunities can be recorded on Worksheet \#4 as a summary sheet.

\section{Step 5: Prioritize Options \& Make Recommendations}

A review of Worksheet \#4 will provide information to determine good opportunities and inadequate ones. Generally, any opportunity with less than a 3-year payback is a good candidate for funding and acceptance. Energy initiatives can have up to a 10-year payback and still be acceptable. Also, any idea that greatly increases safety or helps meet or remove a regulatory burden, as well as reduces waste, is an excellent candidate. These opportunities should be highly recommended for implementation. In the planning for implementation, opportunities that have easily obtained or no implementation costs should be implemented immediately. Others can be designated for later to allow time for more research or funding.

Record all opportunities that were researched even if they failed the feasibility test or were too costly. Recording auditable reasons why a particular action was not done is good to have on record.

These recommendations should be detailed on Worksheet\#5. This worksheet also includes space to record the opportunities and discuss why they were or were not recommended for implementation. 


\section{Example}

\section{Pollution Prevention Opportunity Assessment: Spray Painting}

Polly manages a small parts shop that does custom parts orders, including shop work, welding, spray painting, and assembly. Polly was told by her manager to conduct P2OAs for her shop in order to reduce waste. Both Polly and her manager agreed that reducing waste could increase efficiency and cut costs for their company. Polly first looked at their chemical inputs and discovered that the majority of the hazardous chemicals coming in to the shop were spray painting related. So, she decided to focus on the painting portion of the shop as an Initial goal.

First, Polly listed the main waste streams from the paint shop (see the "Waste Stream Information" worksheet in Appendix B). She listed the volumes of each, then calculated the total cost based on disposal costs provided by her company's P2 group on the back of the worksheet. Spent solvent was the largest and most expensive waste stream. But, she also noted that titanium dioxide used in the sanding process was considered a carcinogen.

Next, she prioritized the four waste streams (see "Priority Streams and Activities" worksheet). She listed the streams in order of total cost, but decided to move the titanium dioxide to the second most important position based on its carcinogenic designation. Then, she listed the activities that contributed to each waste stream.

Working with a small P2 team from her shop, she broke the team into two groups and assigned P2OAs to each. She led the spray painting activity with the help of a few team members.

Before beginning the P2OA, the feam toured the shop carefully, getting a description of the activity from one of the main painters. They talked with the painters and found out that they used solvent for a variety of reasons, including thinning paint and cleaning paint guns. One painter suggested a solvent recovery system, which he had seen at another facility.

Back at the office, the team began the P2OA by listing themselves and describing the activity (see Worksheet \#i). They also created a flowchart of the process, including the air stack emissions from the gun cleaning (see Worksheet \#2). Then the team brainstor med, recording all ideas on a fishbone diagram in short descriptive terms (see Fishbone). Three ideas seemed worth pursuing and each team member took one (see 3 Worksheets \#3). They spent time calling vendors for information about equipment, examining manifests to get specific disposal costs, and pulling procurement records for the cost of materials. They also went back to talk with the painters whenever they needed more information.

The ideas were summarized on one sheet and examined by the team (see

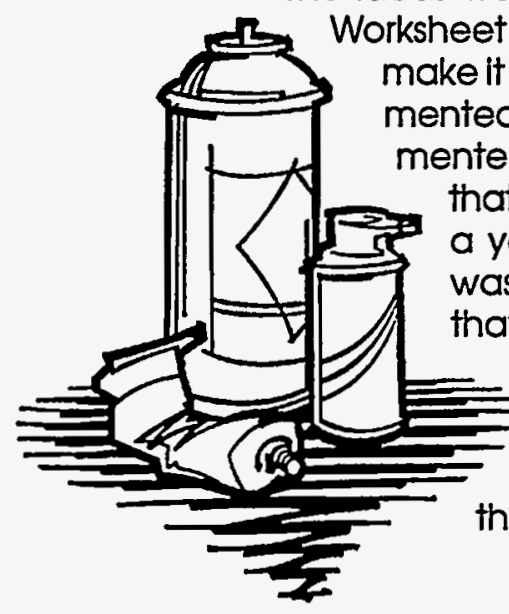
heet \#4). The idea for vinyl lettering would not pay back suf ficiently to make it practical. The idea regarding water-based paints could be implemented without initial cost, so the team thought that idea could be implemented immediately as long as if was for indoor signs. They estimated that the idea about the solvent recovery system would pay back within a year, would save the most money, and would reduce the most waste. so the team agreed that procurement of the capital funds for that project should start right away.

A discussion of the options and the team's recommendation were documented (see Worksheet \#5). Polly presented this package to the $P 2$ group and to her manager, who approved the recommendations.

All Worksheets for this example are in Appendix $B$ 
Reducing pollution is the most important result of the $\mathrm{P} 2 \mathrm{OA}$ process. The critical step in that process is getting the P2 opportunities identified in the P2OA process implemented. This section will outline the approach to choosing which ideas should be implemented as well as suggest funding and support sources. The staps are also listed in Figure 7.

\section{Suggested Approach}

The first step in getting ideas implemented is to carefully choose which to recommend. The previous chapter provided some guidance on how to recommend opportunities. The main factors to consider are: return on investment; implementation cost; position on P2 hierarchy (source reduction, recycling, treatment); and other benefits such as reduction of regulatory burden and safety.

Once the opportunities are prioritized, it may be helpful to write up a small program plan to present to management or to funding sources. The plan can cover all or just some of the ideas to be implemented on the activity reviewed by the P2OA. Use all the information you gathered in the researching stage, especially any cost savings and return on investments calculated. A good place to start is Worksheets \#4 and \#5.

\section{Identifying Funding Sources}

Opportunities that have no implementation cost just need approval to implement, which can often be received from line management. Opportunities that only require expense funds (employee time) can be funded through field pollution prevention budgets or from other funds available within your organization. This is the most stable source of funding and should be sought first. If this funding is insufficient, the next step is to contact the Pollution Prevention Group, who can help you apply for funding directly from DOE-HQ. This funding is much more difficult to receive, though it can be a viable

\section{Figure 7: 4 Steps to Implement a P2 Opportunity}

Choose your initiative carefully

Write a short plan

Find funding

Persevere until it is done! 
Opportunities with a payback of less than 3 years are excellent prospects for funding. option. Please note that direct DOE-HQ funding may not always be available, so encourage your facility $\mathrm{P} 2$ organization to plan for implementation:

Capital expense funds (funds for equipment) are more difficult to receive, but are still achievable. Some funds are available for FY 95 and FY 96 through DOE-HQ via the Pollution Prevention Group; note that these usually require an estimated return on investment of less than three years. Otherwise, funding must be requested through the budgeting process of your own organization. The coordinator of your facility P2 team will have information on this process. The Pollution Prevention Group also can help provide advice and guidance. 
Now that you have completed several P2OAs and implemented some initiatives, you can and should take credit for your work. Some reporting is required because it will keep you in compliance with RCRA and a variety of other regulations. Other reporting is optional, but it will help show that your organization is successful at reducing waste and saving money.

This section discusses what information you should track as well as to what sources you should report.

\section{Tracking Techniques}

The most obvious way to track is to retain and file your P2OA forms. This can be done in hard copy, soft copy, or both. With each set of P2OA forms, keep background research information and contacts. Also, keep track of any information and budget data on opportunities implemented. That way you can track the outcome of each P2OA.

A summary tracking report may also be useful to show the overall success of your P2OA program. This form will summarize the actual opportunities implemented. The main summary pieces of success data that you may want to track for each opportunity are:

- Opportunity implemented

- $\mathrm{P2OA}$ resulting in the opportunity

- Waste class(es) reduced

- Waste stream(s) reduced

- Volume of waste(s) reduced

- Implementation cost

- Annual or onetime cost savings

- Payback period.

Tracking your activities keeps you in compliance and helps showcase your success.

The Pollution Prevention Group is developing a P2OA tracking system that also can be used for tracking success and compliance. The first phase of this tracking system should be available in spring of 1995. Inputting P2OA results into this Hanford tracking system will not only help teams track their P2OA progress, but will help create required reports and share $\mathrm{P} 2$ successes with other Hanford employees and DOE sites. 
Getting Credit for Your Work-Who to Tell

The required reporting for each P2OA is basically the five worksheets (or a method of your choice) detailing the P2OA process. These can be submitted to the $\mathrm{P} 2$ group as you conduct them, or on a quarterly or yearly basis. Additionally, a brief update on the number of $\mathrm{P} 2 \mathrm{OAs}$ conducted and the status or progress of the $\mathrm{P} 2$ opportunities

For information from the WHCP2 Group, call the Pollution Prevention Hotline: $376-6239$ for each also should be submitted. The specifics for required reporting are detailed in Compliance Guidance available from the P2 Group.

Not only should accomplishments be recorded for reporting and regulatory reasons, successes should be communicated for the benefit of you and others. By telling people about the P2 you have achieved, you not only reveal yourself as a quality group, but the technique or technology can be transferred to other facilities or Sites that have similar problems. Some methods of achieving this are:

- Posting on a facility bulletin board

- Application for ECCEL credit

- Article in a technical magazine, such as Pollution Engineering or Pollution Prevention Review

- Presentation at a technical conference, such as the DOE Pollution Prevention Conference or the Air and Waste Management Association Annual Conference.

- Article in a newsletter, such as Pollution Prevention Advisor

- Article in the Hanford Reach (The P2 Group writes a series of articles under the tag "Pollution Prevention Pays." They can help you write the article and help you get it published.)

- Submission to the Hanford Pollution Prevention Accomplishments Book (done by the Pollution Prevention Group)

- Application for awards, such as DOE Pollution Prevention Awards or Westinghouse Corporate Awards.

The P2 Group has information about how to write articles or submit information for publication, or how to apply for many of these awards.

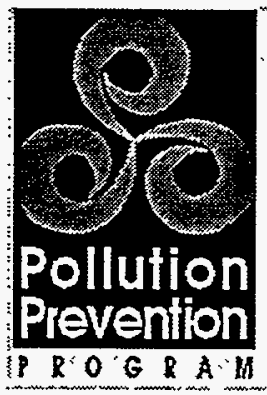

\section{Hanford Pollution Prevention Accomplishments Book}

The Accomplishments Book

(1)

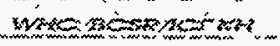

is one of many places to

report success. 
Also remember to document any "failures." These could include ideas that were not approved or did not perform as expected. These may be used as lessons learned for the next time or for another facility. If the problem was solved via another means, that also should be recorded as a lesson learned for yourself and others. 


\subsection{How to Deal with Special Problems (Troubleshooting)}

The method described in the previous sections seeks to be generic so that it can be adapted to all facilities and activities at the Hanford Site. Hanford is unique in its mission of environmental restoration, and in its variety of facility activities. Almost no facility has only routine processes and some have almost none at all.

This section is designed to address areas in which P2OAs have not traditionally been used. The two most common myths about P2OAs are that they cannot be used on nonroutine waste streams or on complex laboratory processes. By modifying at the point at which the activity $\mathrm{P} 2 \mathrm{OAs}$ are conducted or by changing one's point of view, P2OAs can be conducted on these and most other activities.

\section{Project-Oriented Activities}

Some facilities or groups conduct activities only on a project-oriented basis, meaning each waste generating activity is only done once. An example is an engineering lab that builds prototypes or does service kinds of experiments. Each project has unique chemical inputs, a defined length of time, and very specific activities.

Project-oriented waste generating activities can be addressed by P2OAs in two ways. First, a macro-level view can be taken, looking for consistent general activities that occur. Such activities can include material procurement or personal protective clothing use. These waste sources can be reviewed using a standard P2OA, resulting in facilitywide waste reducing ideas, such as procurement control or procedure changes.

The second way to address projects is to implement the P2OA at the planning phase. This means reviewing the project scope and project plan in the same way an ongoing activity would be reviewed, although on paper. The steps can be mapped, inputs and outputs identified, and brainstorming done on areas that will generate waste. All applicable and cost-effective ways of reducing waste can then be written into the project plan. In-line with this method is to make sure that at least one member of the planning team is a P2 advocate and will actively speak up for any P2 initiatives.

\section{DED/ER Waste Streams}

The waste streams from decontamination and decommissioning (D\&D)/environmental restoration (ER) activities are often considered "nonroutine" and project oriented. This is because D\&D usually

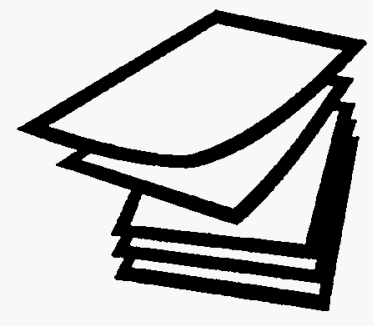

Forprojects, do P2

when you plan!

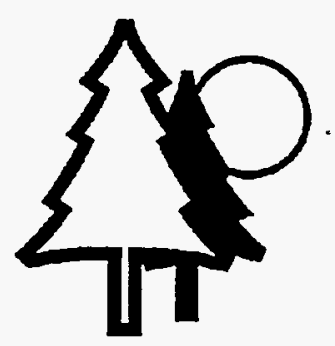


3 Ways to Do ER/ D\&D P2OAs: Take a macro view, Include in planning. Consider routine over time.

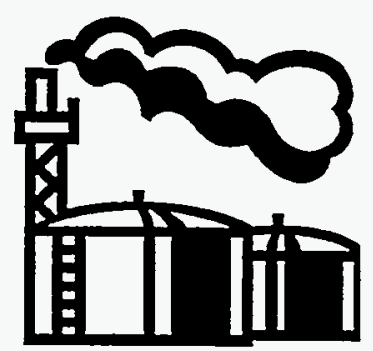

involves removing buildings, and ER usually means washing soil and returning the land to its natural state. Thus, just as project wastes can be addressed on a macro level or in the planning phases, the same can also be said about D\&D/ER wastes.

Therefore, the first two ways to address this area is to review the two steps described in the Project Oriented Activities portion of this section. First, address common waste streams such as personal protective clothing and material inputs on a macro level. Second, conduct paper P2OAs during the planning phase.

The third way to consider D\&D/ER waste streams at Hanford is to not consider them nonroutine, but to view them as part of a long series of routine processes. An example of this would be D\&D of buildings. As there are some 300 buildings on Site slated for demolition in the next 30 years, the entire schedule can be viewed as a regular activity to be conducted 300 times. This perspective allows you to consider equipment and initiatives that can be used on multiple projects, as well as develop lessons learned from one to another.

A special concern on D\&D/ER waste streams is that a large portion of the waste is already "generated." Since the activities involve cleaning up or tearing down existing wastes or structures, some claim that no pollution prevention can be accomplished. Employees at Hanford have already proved that $\mathrm{P} 2$ can be accomplished by extensive recycling of concrete and steel from D\&D. The key is to prevent generation of secondary waste as much as possible (source reduction) but to accept and embrace recycling as an excellent and viable method of P2 for D\&D/ER waste streams.

The most critical thing about $D \& D / E R$ waste streams is to realize that the activities that generate these wastes are the ultimate mission of Hanford. An open mind to pollution prevention and all P2 options can successfully result in waste reduction from D\&D/ER.

\section{Facility Design/Modification}

Just as Decontamination and Decommissioning of buildings has P2 challenges, so does its opposite: new facility design and modification. However, while D\&D/ER can achieve significant recycling successes, design offers excellent opportunities, in the planning phase, for source reduction and energy conservation.

The way to address pollution prevention for these activities is to consider ideas in the design phase. This includes looking at P2 for the actual construction of the structure and P2 during the building's planned regular use. Ideas can range from recycling of construction materials, minimizing waste through location of equipment, and the 
use of high-efficiency lighting and power sources. The WHC Pollution Prevention Group has developed a Design Training and Guideline to provide $\mathrm{P} 2$ ideas in the design phase. More information can be received on this by contacting the Pollution Prevention Group.

\section{Laboratory Activities}

On the other end of the scale from large onetime projects, is laboratory analysis. Analytical labs often have thousands of procedures and processes in any year. The traditional argument against using P2OAs on lab activities is that there are too many to analyze, therefore it would not be cost effective.

The best way to conduct P2OAs on lab activities is to examine the general activities done throughout the $\mathrm{lab}$ and group those together. Then, P2OAs can be conducted on groups of activities all contributing basically to the same waste streams. An example of this is to do a P2OA on hood activities, i.e., material inputs and waste streams from lab analyses done in hoods.

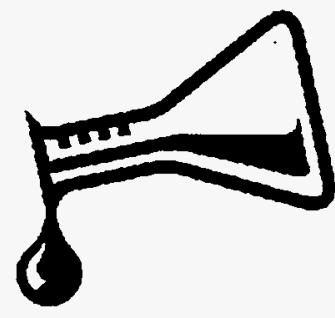

Also, just as for project-oriented waste streams, $\mathrm{P} 2 \mathrm{OAs}$ can be done on a macro-level, such as procurement and personal protective cloth-

Forlab P2, group your many activities together. ing. When doing these, do not forget that ideas from smaller P2OAs often yield initiatives that could have wider applications throughout a lab, so you can start there for ideas. 


\subsection{Conclusion}

Pollution Prevention Opportunity Assessments are just one way of "doing P2." Many ideas for Pollution Prevention will come about from people having a good idea spontaneously. Some pollution prevention activities are being done and have not been called "Pollution Prevention." Many people do pollution prevention on their own and ask for no acknowledgment or recognition; it is their right way of doing business. All these methods are fine. Hopefully, P2OAs and this Guide will help spark other ideas that have yet to be discovered.

If you have any questions, need any help, or are seeking technical information on pollution prevention, please feel free to call anyone in the Pollution Prevention Group at Westinghouse Hanford. Appendix $C$ lists the members, as well as the specific contacts for each facility. You can call your assigned contact, who is up-to-date on your facility, or any other member. For more information, Appendix D gives other help numbers, references, and technical solutions.

A P2OA only brings you to the idea, you need to see it through to implementation. Use P2OAs and any other resources you may have to discover new opportunities. Then, go out and reduce waste! 
Appendix A: Blank Worksheets

This Appendix contains the blank worksheets for prioritizing your waste streams and for conducting P2OAs.

The prioritizing worksheets include the following:

- "Waste Stream Information" Worksheet

- "Priority Streams and Activities" Worksheet

The P2OA worksheets include the following:

-Worksheet 1: Team \& Activity Description

-Worksheet 2: Activity Flow Diagram

-Worksheet 3: Pollution Prevention Opportunity Description

-Worksheet 4: Pollution Prevention Opportunities Summary

-Worksheet 5: Final Summary

The following worksheet may also be used to help with your brainstorming sessions:

- Fishbone Diagram 


\section{Waste Stream Information}

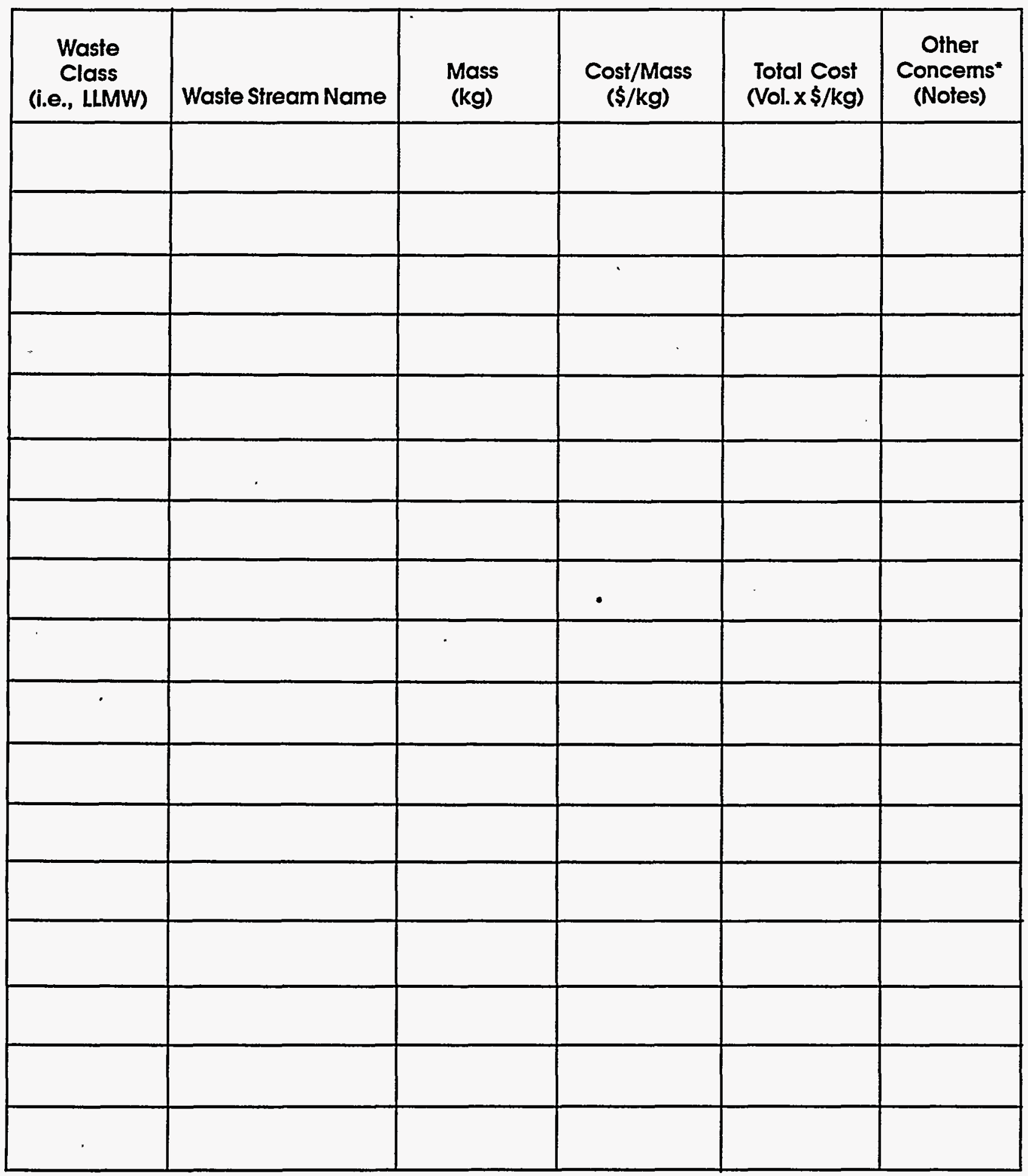




\section{Guidelines for Waste Stream Information}

This worksheet helps a P2 team prioritize waste streams and document summary information. Using the waste projections provided by Pollution Prevention:

1. Identify the three largest streams for each waste class. Record the waste class, the waste stream name, and the projected waste volume on the worksheet. Important sanitary waste streams can also be identified on this worksheet, if these are a priority or can easily be reduced.

2. Using the table below, identify the cost per mass (disposal cost) for each waste stream and record it in the Cost Per Mass column.

\begin{tabular}{|c|c|c|c|c|c|}
\hline Waste Class & LLW & LLMW & TRU & Hazardous & Sanitary \\
\hline$\$ / \mathrm{kg}$ & $\$ 1.76$ & $\$ 5.08$ & $\$ 3.68$ & $\$ 1.87$ & $\$ 0.07$ \\
\hline
\end{tabular}

3. Multiply the projected waste quantity of each waste stream by the volume cost of the waste and enter the amount in the Total Cost column.

4. Identify any other factors* to be considered with the individual waste streams and record a key word for this factor in the Other Concerns column. P2 teams will have to determine the weight given these other factors. The Other Concerns column is designed to provide flexibility for teams to attend to specific management or environmental priorities.

*toxicity, regulatory, safety, ALARA, etc. 


\section{Priority Streams and Activities}

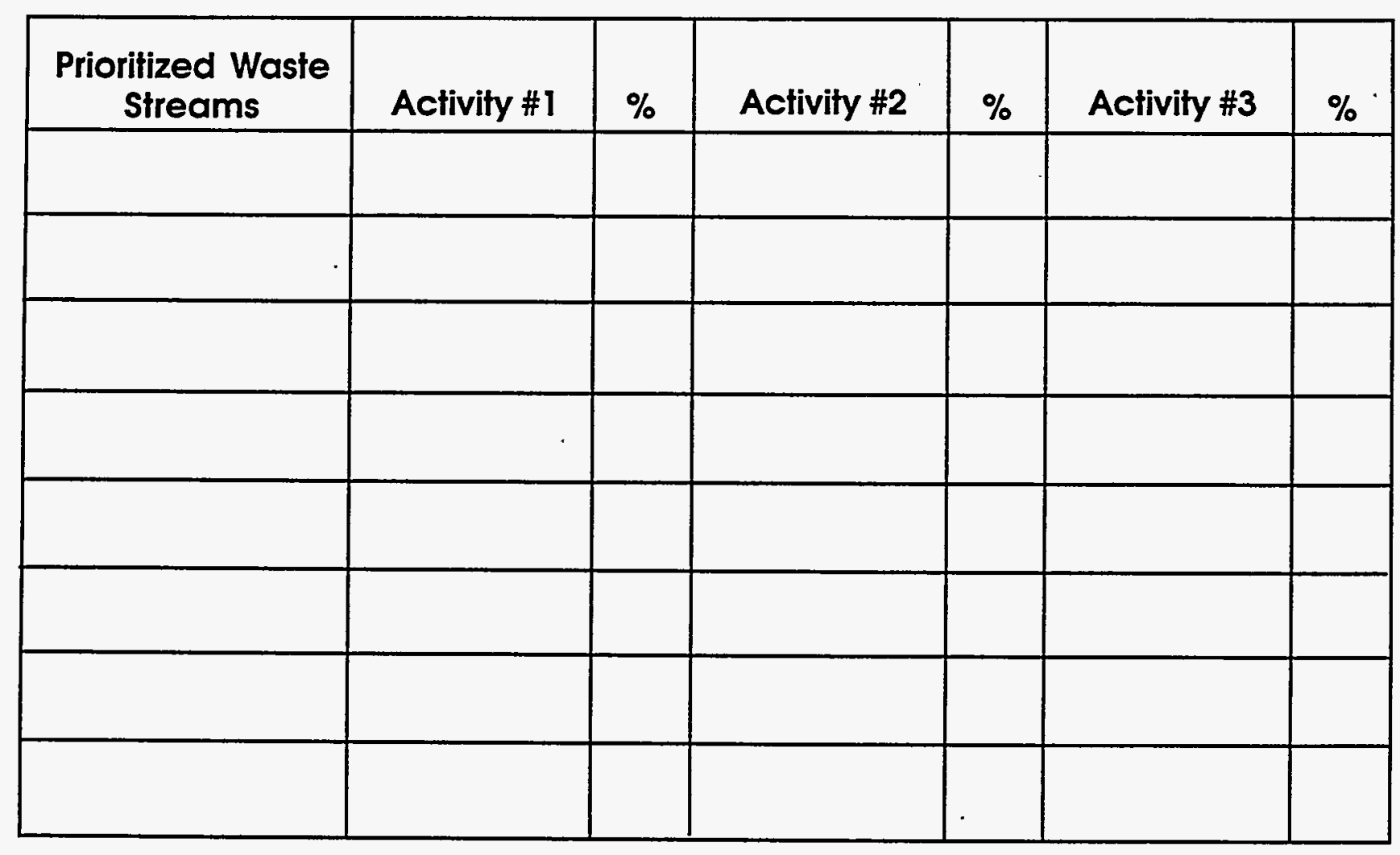




\section{Guidelines for Priority Streams and Activities}

With the waste streams identified, the $\mathrm{P} 2$ team is ready to prioritize the streams and

- major activities generating them.

1. Prioritize waste streams identified on the Waste Stream Information Worksheet by highest total cost, accounting for other appropriate prioritizing factors*. Order these on the Priorities Streams and Activities Worksheet.

2. Identify the major activities generating each of these waste streams. While the form allows identification of the top three waste stream producing activities, more or less activities can be identified as appropriate. It would also be appropriate to list on this worksheet activities that could easily be changed to achieve waste reduction, e.g., "low hanging fruit".

This step will involve contacting key individuals in the facility. Important individuals to begin with would be the hazardous materials coordinator and the Environmental Compliance Officer.

3. Determine the approximate percentage of waste each activity contributes to the total waste stream. Enter this amount in the \% column.

*toxicity, regulatory, safety, ALARA, etc. 


\section{Pollution Prevention Opportunity Assessment WORKSHEET 1 Team \& Activity Description}

Date: ___ _ _ P2OA ID Code:

Facility:

Activity:

Team Members (*Leader)

1

Telephone

MSIN

Description of Activity to be Examined in this P2OA 


\section{Guidelines for Worksheet 1}

This worksheet provides the scope and identification of the pollution prevention opportunity assessment (P2OA) team. For the P2OA to be successful, employees involved with the activity being assessed should be members of the team. The assessment team needs a leader, members, and additional resources, as required.

The team leader should have technical knowledge of the area's operations and the personnel involved. The leader assembles the team to perform the assessment. Team members may include engineers, waste generators, waste management specialists, scientists, operators, laboratory technicians, and other line personnel. Additional resources may be utilized to provide information not available within the team, including interviews with line personnel, procurement and health and safety, as well as research of technical publications/case studies. The size of the team may be large for complicated operations, but should be kept to a minimum to maintain focus.

1. Date: List the initiation date for this P2OA.

2. P2OA ID Code: List the P2OA ID Code selected by the team or facility. This should be a unique identifier.

3. Facility: List the facility in which this P2OA is being examined.

4. Activity: List the activity contributing to the waste stream.

5. Team Members, Phone, MSIN: To facilitate team meetings and for future reference, this information should be completed when the P2OA team is formed.

6. Activity Description: This section should list the main activities contributing to the waste stream that are to be examined in this P2OA. Remember that this waste stream can be examined again in a future P2OA with a different activity focus, so limit the activities to be examined in a single P2OA to no more than three. If activities are very diverse, complete separate worksheets for each. A description of each activity should be listed, including pollution prevention activities already in place. Be sure and include the purpose or goal of the activity, schedule or frequency of activity, materials used, steps taken to complete the activity, and all wastes generated by each step. Items such as equipment, controls, operators, and operator training (qualification or certification) may also be included. 


\section{Pollution Prevention Opportunity Assessment WORKSHEET 2 Activity Flow Diagram}

Date: P2OA ID Code:

Facility:

Activity:

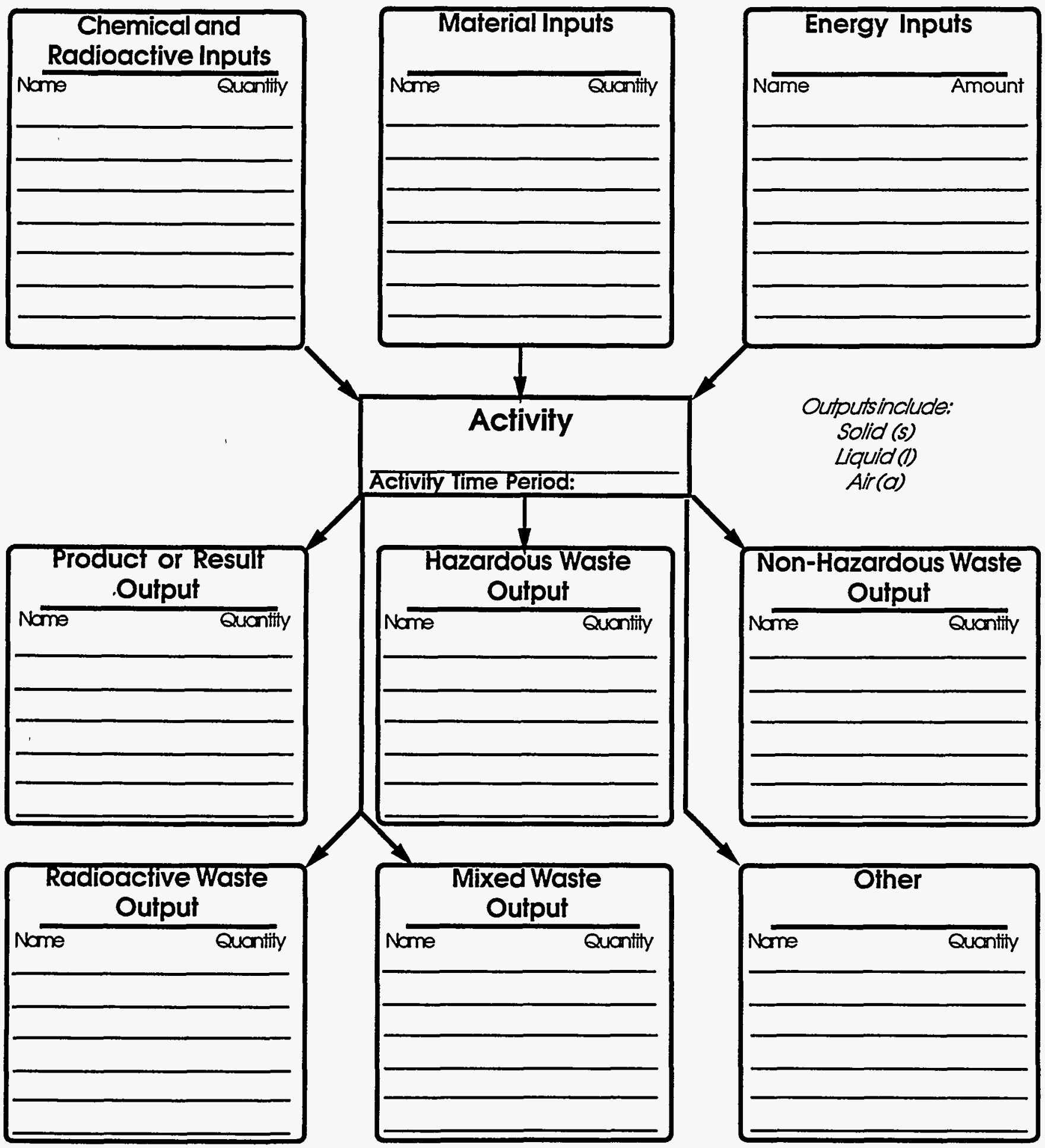

Total Input mass $\approx$ Total Output mass? $\mathrm{kg} \ln \approx$ $\mathrm{kg}$ Out 


\section{Guidelines for Worksheet 2}

This worksheet provides a method to document the activity flow diagram for the assessment. The flow diagram should identify all inputs (materials/resources) and outputs (products/wastes). The flow diagram should track materials from the time they enter the process boundary until they leave. This diagram represents a very simplistic flow model and is meant to be a guideline. If desired or if the activity is very complex, a more detailed diagram may be completed to identify all waste streams, especially for complex, multi-step processes. Several forms can be completed if several activities contribute to the waste stream of interest.

Please note that, although the focus may be on one priority waste stream, an analysis should be conducted on all material inputs and outputs. This is because the reduction of one waste may affect others in the activity (and you want to take credit for those too!). Additionally, while looking at an activity, it is cost and time effective to look at all waste streams and materials for possible reduction opportunities.

1. Date, P2OA ID Code, Facility, Activity: List the date this sheet is completed, the unique P2OA ID code, facility, and the examined activity for this P2OA from Worksheet 1.

2. Activity: Fill in the Activity Name box with the activity being examined.

3. Activity Time Period: List the time period for the activity being examined, such as, the complete clean-up, one analysis, yearly, etc.

4. Inputs: List the input materials on the lines provided, including hazardous materials, non-hazardous materials, and energy sources. Don't forget to include resource inputs such as water, cleanup supplies, reusable supplies, anything that ends up as a waste, is used and cleaned, or is used up during the activity.

5. Outputs: Fill in the outputs, both useful items and wastes, in the boxes. Include all manifested and non-manifested wastes, plus air emissions, if any.

6. Material Balance: A rough material balance can be conducted (making sure the inputs equal the outputs), to determine if most of the input and output materials have been captured. Energy inputs will not be included in the material balance. 


\section{Pollution Prevention Opportunity Assessment WORKSHEET 3 Pollution Prevention Opportunity Description}

Date: P2OA ID Code: Facility:

Activity:

P2O No. P2O Title:

Current Practice:

Recommended Action:

Calculation of Waste Reduction and/or Energy Savings:

Calculation of Annual Cost Savings:

Calculation of Implementation Cost and Payback: 


\section{Guidelines for Worksheet 3}

Before these summary sheets can be completed, the team should hold a brainstorming session to develop Pollution Prevention Opportunities (P2Os). Brainstorming sessions are effective ways for individuals to generate options and should occur in an environment that encourages creativity and independent thinking. A knowledge of the activity is essential before the brainstorming session. Provided below is a fishbone diagram that may help the team generate ideas.

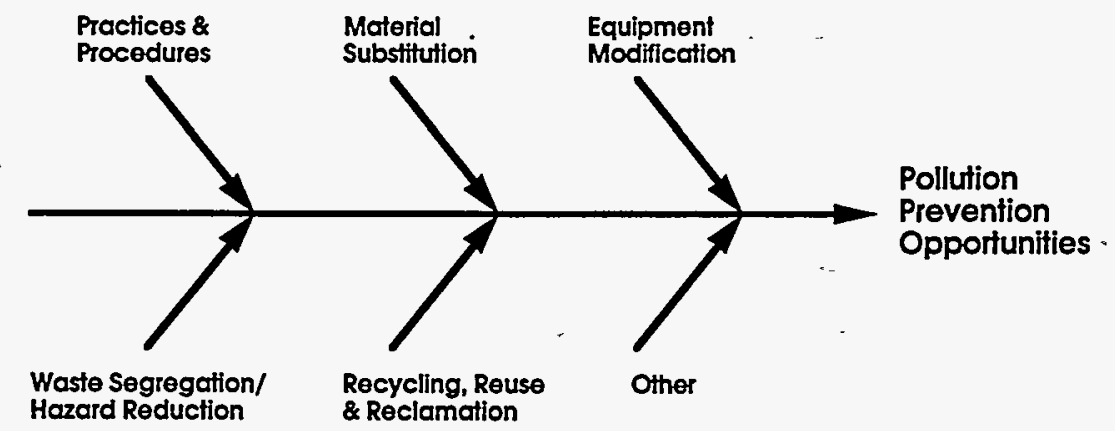

Promising P2Os from the brainstorming session should then be researched by individual teams members. This is in order to determine specifics related to the P2Os, and may involve calls to vendors or procurement, discussions with engineers, talking to line personnel and others. Considerable calculations and notes will most likely be taken on other sheets during the process. When complete, each idea's information can then be recorded on this summary sheet, which serves as a method to record and evaluate the options that have been identified.

1. Date, P2OA ID Code, Facility, Activity: List the date this sheet is completed, the unique P2OA ID code, facility, and the examined activity for this P2OA from Worksheet 1.

2. $\quad P 2 O$ No. and P2O Title: A number should be assigned to each $\mathrm{P} 2 \mathrm{O}$ from the complete brainstorm list and written here. The title should be descriptive of the recommendation, starting with an action verb (e.g, replace, modify, install, insulate, develop, reduce, retrofit, educate).

3. Current Practice: Briefly describe the current practice as it relates to this opportunity, so that the action described next can be fully understood.

4. Recommended Action: Describe what the change will be and how it will reduce waste or save energy.

5. Calculation of Waste Reduction and/or Energy Savings: Briefly describe the methodology used to determine waste and energy reductions. Cite references. List calculations as necessary to provide specific numbers. Be specific as to what the waste reduced consists of and what waste type is reduced (LLW, Mixed, Haz).

6. Calculation of Annual Cost Savings: Briefly describe the methodology used to determine cost savings. Cite references. List calculations as necessary to provide specific numbers. State the specific estimated costs savings for one year after implementation is complete.

7. Calculation of Annual Cost Savings \& Payback: Briefly describe the methodology used to determine implementation costs. Cite references. List calculations as necessary to provide specific values. Calculated payback as: implementation cost divided by annual savings. 


\section{Pollution Prevention Opportunity Assessment WORKSHEET 4 \\ Pollution Prevention Opportunities Summary}

Date:

P2OA ID Code:

Facility:

Activity:

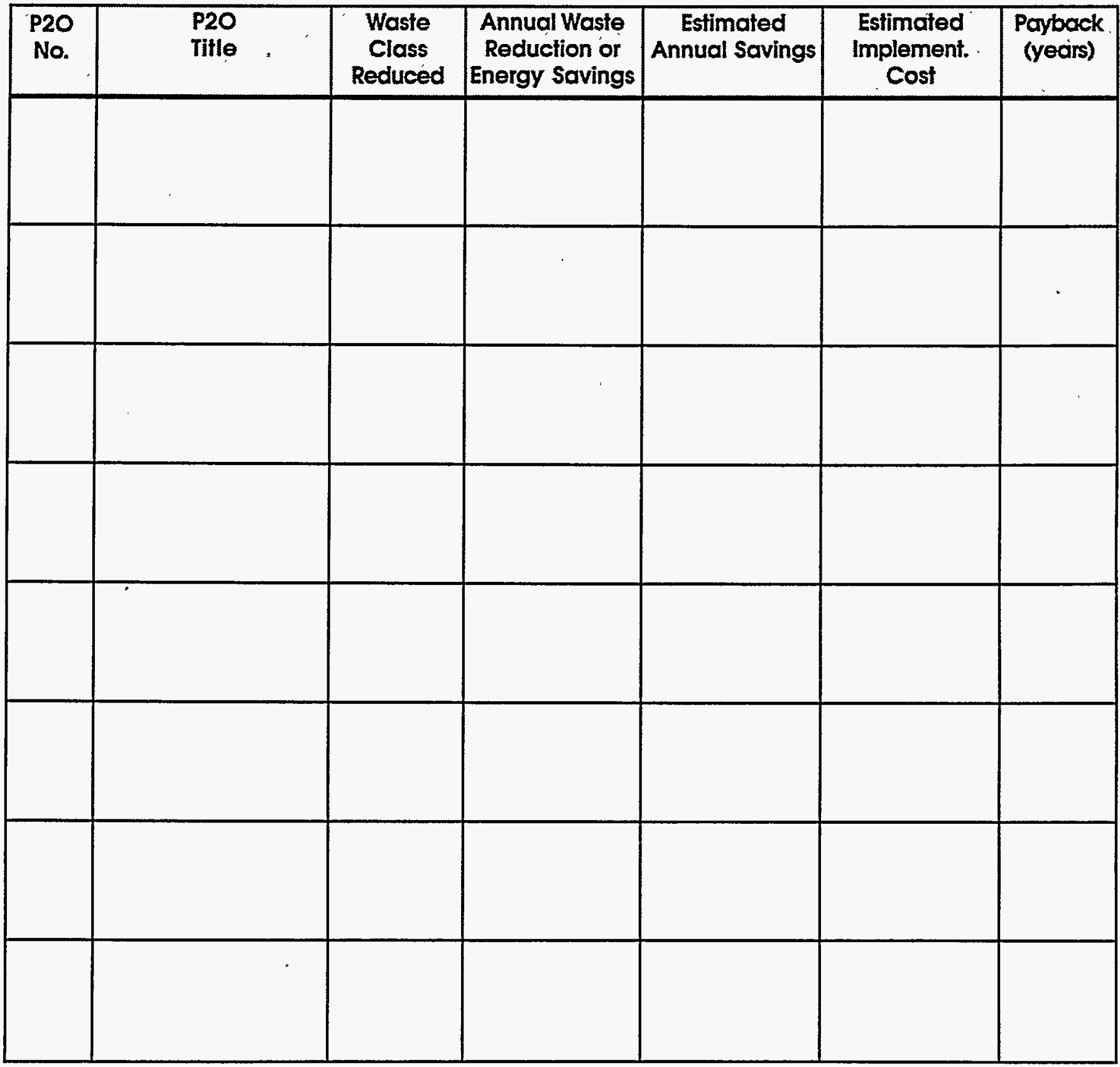

Notes and Other Benefits: 


\section{Guidelines for Worksheet 4}

This worksheet is meant as a simple way to compare the P2Os with each other after the research and feasibility analysis has been completed. They can be listed according to the P2 hierarchy (source reduction first, followed by recycling/reuse, and treatment). They can also be listed according to the shortest payback, either within each hierarchy level or overall.

1. Date, P2OA ID Code, Facility, Activity: List the date this sheet is completed, the unique P2OA ID code, facility, and the examined activity for this P2OA from Worksheet 1.

2. P2O No., Title, Waste Class, Reduction, Savings, Implementation, and Payback: These values can all be entered directly from the sections in Worksheets 3 . If a savings or a implementation cost is very small, write 'negligible.' Just because an idea is not cost-effective or a large waste reducer, does not mean it should not be listed-it may be a simple"low-hanging fruit" that can be accomplished giving instant success or good public relations. Some ideas may ease compliance with regulations, or resolve a safety concern and thus should be considered also.

3. Notes and Other Benefits: The notes section can include any regulatory drivers for a particular $\mathrm{P} 2 \mathrm{O}$ or other important issues besides cost or $\mathrm{P} 2$ hierarchy to be considered. 


\section{Pollution Prevention Opportunity Assessment WORKSHEET 5 \\ Final Summary}

Date:

P2OA ID Code:

Facility:

Activity:

Proposed Opportunities and Disçussion:

Recommendations \& Schedule for Implementation: 


\section{Guidelines for Worksheet 5}

This sheet provides a brief summary about the whole assessment. Its purpose is to document how this assessment was performed, the conclusions reached by the team, and the recommendations for further actions. For a more complex assessment, a longer, more formal executive summary may want to be written out for presentation to management.

1. Date, P2OA ID Code, Facility, Activity: List the date this sheet is completed, the unique P2OA ID code, facility, and the examined activity for this P2OA from Worksheet 1.

2. Proposed Opportunities and Discussion: Briefly describe the main opportunities examined, including the waste streams or input material to be minimized, benefits achieved, and any positive and negative aspects to the opportunities.

3. Recommendations \& Schedule for Implementation: Briefly describe any actions that

- should or will be taken in respect to this assessment. Provide a recommendation for date of implementation. 


\section{Brainstorming for: Pollution Prevention Opportunities}

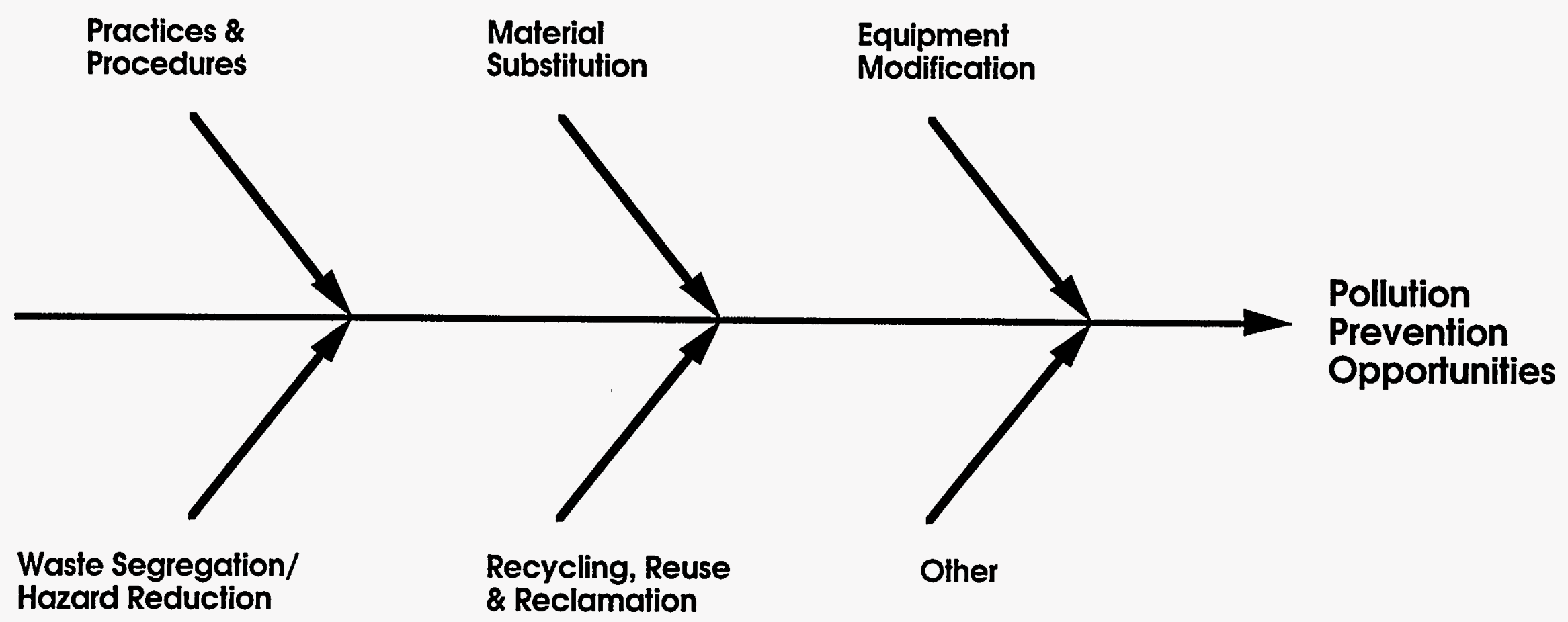


P2OAs: GUIDANCE FOR THE HANFORD SITE

Appendix B: Spray Painting P2OA Example Worksheets

This Appendix contains the completed worksheets for the example described on page 15. These include the worksheets for prioritizing waste streams and for conducting the P2OA.

The worksheets include the following:

- "Waste Stream Information" Worksheet

- "Priority Streams and Activities" Worksheet

- Worksheet 1: Team \& Activity Description

- Worksheet 2: Activity Flow Diagram

- Fishbone: Brainstorming for Painting P2 Opportunities

-Worksheet 3: Pollution Prevention Opportunity Description

-Worksheet 4: Pollution Prevention Opportunities Summary

-Worksheet 5: Final Summary 


\section{Waste Stream Information}

\begin{tabular}{|c|c|c|c|c|c|}
\hline $\begin{array}{c}\text { Waste } \\
\text { Class } \\
\text { (i.e., LLMW) }\end{array}$ & Waste Stream Name & $\begin{array}{l}\text { Mass } \\
(\mathrm{kg})\end{array}$ & $\begin{array}{c}\text { Cost/Mass } \\
(\$ / \mathrm{kg})\end{array}$ & $\begin{array}{l}\text { Total Cosł } \\
\text { (Vol. } \times \$ / k g)\end{array}$ & $\begin{array}{c}\text { Other } \\
\text { Concems* } \\
\text { (Notes) }\end{array}$ \\
\hline Hazardous & SpentSolvent & 7,600 & $\$ 1.87$ & $\$ 14,180$ & \\
\hline Hazardous & Oil-Basedpaint & 1,900 & $\$ 1.87$ & $\$ 3,545$ & \\
\hline Sanitary & Sand & 1,000 & $\$ 0.07$ & $\$ 0$ & \\
\hline Hazardous & TitaniumDioxide & 0500 & $\$ 1.87$ & $\$ 933$ & Carcinogen \\
\hline & & & & & \\
\hline & & & & & \\
\hline & & & & & \\
\hline & & & & & \\
\hline & & & & & \\
\hline & & & & & \\
\hline & & & & & \\
\hline & & & & & \\
\hline & & & & & \\
\hline & & & & & \\
\hline & & & & & \\
\hline & & & & & \\
\hline & & & & & \\
\hline
\end{tabular}




\section{Guidelines for Waste Stream Information}

This worksheet helps a P2 team prioritize waste streams and document summary information. Using the waste projections provided by Pollution Prevention:

1. Identify the three largest streams for each waste class. Record the waste class, the waste stream name, and the projected waste volume on the worksheet. Important sanitary waste streams can also be identified on this worksheet, if these are a priority or can easily be reduced.

2. Using the table below, identify the cost per mass (disposal cost) for each waste stream and record it in the Cost Per Mass column.

\begin{tabular}{|c|c|c|c|c|c|}
\hline Waste Class & LLW & LLMW & TRU & Hazardous & Saniłary \\
\hline$\$ / \mathrm{kg}$ & $\$ 1.76$ & $\$ 5.08$ & $\$ 3.68$ & $\$ 1.87$ & $\$ 0.07$ \\
\hline
\end{tabular}

3. Multiply the projected waste quantity of each waste stream by the volume cost of the waste and enter the amount in the Total Cost column.

4. Identify any other factors* to be considered with the individual waste streams and record a key word for this factor in the Other Concerns column. P2 teams will have to determine the weight given these other factors. The Other Concerns column is designed to provide flexibility for teams to attend to specific management or environmental priorities.

*toxicity, regulatory, safety, ALARA, etc. 


\section{Priority Streams and Activities}

\begin{tabular}{|c|c|c|c|c|c|c|}
\hline $\begin{array}{c}\text { Priorifized Waste } \\
\text { Streams }\end{array}$ & Activity \#1 & $\%$ & Activity \#2 & $\%$ & Activity \#3 & $\%$ \\
\hline 1. SpentSolvent & Spraypainting & 80 & $\begin{array}{l}\text { Machining } \\
\text { Parts Cleaning }\end{array}$ & 20 & & \\
\hline 2. TitaniumDioxide & SandingObjects & 100 & & & & \\
\hline 3. Oil-Basedpaint & Spraypainting & 100 & & & & \\
\hline 4. Sand & SandBlasting & 100 & & & & \\
\hline & & & & & & \\
\hline & & & & & & \\
\hline & & & & & & \\
\hline
\end{tabular}




\section{Guidelines for Priority Streams and Activities}

With the waste streams identified, the P2 team is ready to prioritize the streams and major activities generating them.

1. Prioritize waste streams identified on the Waste Stream Information Worksheet by highest total cost, accounting for other appropriate prioritizing factors*. Order these on the Priorities Streams and Activities Worksheet.

2. Identify the major activities generating each of these waste streams. While the form allows identification of the top three waste stream producing activities, more or less activities can be identified as appropriate. It would also be appropriate to list on this worksheet activities that could easily be changed to achieve waste reduction, e.g., "low hanging fruit".

This step will involve contacting key individuals in the facility. Important individuals to begin with would be the hazardous materials coordinator and the Environmental Compliance Officer.

3. Determine the approximate percentage of waste each activity contributes to the total waste stream. Enter this amount in the \% column.

*toxicity, regulatory, safety, ALARA, etc. 


\section{Pollution Prevention Opportunity Assessment WORKSHEET 1 Team \& Activity Description.}

Date: $4 / 8194$ P2OA ID Code: Solv-1 Facility:_paint Shop

Activity: Spraypainting

Team Members ( ${ }^{*}$ Leader) Telephone

MSIN

pollypaulson*

SteveSorenson

TomThompson

Carrie Carlson

$372-1259$

$97-77$

$376-8126$

$96-23$

$372-4352$

H422

$376-6783$ 13-54

Description of Activity to be Examined in this P2OA

Solventis used as a thinner and cleanerin the process of spraypainting and stenciling signs, equipment and fabricated objects. Solvent is used to clean: (1) the inside of the spray gun by spraying solvent through the gun upon completion of theprocess; (2) the outside of the spray gun by wiping down the gun with a rag and solvent; (3) the object beforepainting by wiping down theobject with a rag and solvent. Solvent is also used as a thinner for oil-based paints. Thespentsolventisshipped offsite as hazardouswastefor disposal. The airfrom the paintbooth is sentthrough a series of filters before beingemitted to the atmosphere. The filters are replaced when dirty and disposedofasnon-requlated waste. 


\section{Guidelines for Worksheet 1}

This worksheet provides the scope and identification of the pollution prevention opportunity assessment (P2OA) team. For the P2OA to be successful, employees involved with the activity being assessed should be members of the team. The assessment team needs a leader, members, and additional resources, as required:

The team leader should have technical knowledge of the area's operations and the personnel involved. The leader assembles the team to perform the assessment. Team members may include engineers, waste generators, waste management specialists, scientists, operators, laboratory technicians, and other line personnel. Additional resources may be utilized to provide information not available within the team, including interviews with line personnel, procurement and health and safety, as well as research of technical publications/case studies. The size of the team may be large for complicated operations, but should be kept to a minimum to maintain focus.

1. Date: List the initiation date for this P2OA.

2. P2OA ID Code: List the P2OA ID Code selected by the team or facility. This should be a unique identifier.

3. Facility: List the facility in which this $\mathrm{P} 2 \mathrm{OA}$ is being examined.

4. Activity: List the activity contributing to the waste stream.

5. Team Members, Phone, MSIN: To facilitate team meetings and for future reference, this information should be completed when the P2OA team is formed.

6. Activity Description: This section should list the main activities contributing to the waste stream that are to be examined in this P2OA. Remember that this waste stream can be examined again in a future P2OA with a different activity focus, so limit the activities to be examined in a single P2OA to no more than three. If activities are very diverse, complete separate worksheets for each. A description of each activity should be listed, including pollution prevention activities already in place. Be sure and include the purpose or goal of the activity, schedule or frequency of activity, materials used, steps taken to complete the activity, and all wastes generated by each step. Items such as equipment, controls, operators, and operator training (qualification or certification) may also be included. 


\section{Pollution Prevention Opportunity Assessment WORKSHEET 2 Activity Flow Diagram}

Date: $418 / 94$ P2OA ID Code: Solv-1

Facility: paintshop

Activity:___ Spraypainting

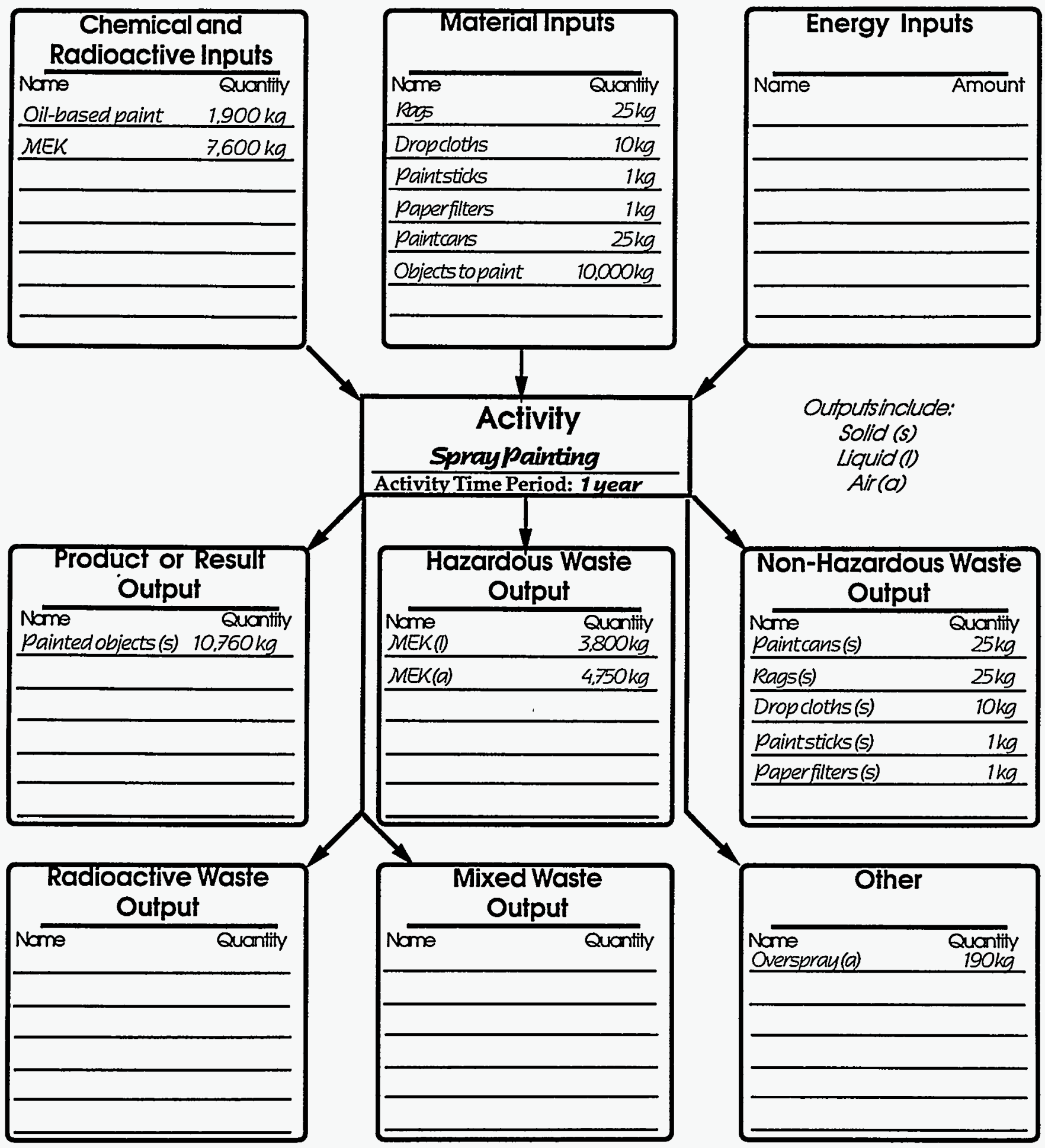

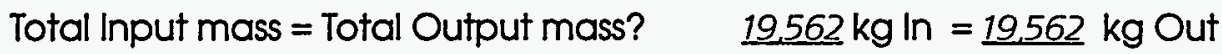




\section{Guidelines for Worksheet 2}

This worksheet provides a method to document the activity flow diagram for the assessment. The flow diagram should identify all inputs (materials/resources) and outputs (products/wastes). The flow diagram should track materials from the time they enter the process boundary until they leave. This diagram represents a very simplistic flow model and is meant to be a guideline. If desired or if the activity is very complex, a more detailed diagram may be completed to identify all waste streams, especially for complex, multi-step processes. Several forms can be completed if several activities contribute to the waste stream of interest.

Please note that, although the focus may be on one priority waste stream, an analysis should be conducted on all material inputs and outputs. This is because the reduction of one waste may affect others in the activity (and you want to take credit for those too!). Additionally, while looking at an activity, it is cost and time effective to look at all waste streams and materials for possible reduction opportunities.

1. Date, P2OA ID Code, Facility, Activity: List the date this sheet is completed, the unique P2OA ID code, facility, and the examined activity for this P2OA from Worksheet 1 .

2. Activity: Fill in the Activity Name box with the activity being examined.

3. Activity Time Period: List the time period for the activity being examined, such as, the complete clean-up, one analysis, yearly, etc.

4. Inputs: List the input materials on the lines provided, including hazardous materials, non-hazardous materials, and energy sources. Don't forget to include resource inputs such as water, cleanup supplies, reusable supplies, anything that ends up as a waste, is used and cleaned, or is used up during the activity.

5. Outputs: Fill in the outputs, both useful items and wastes, in the boxes. Include all manifested and non-manifested wastes, plus air emissions, if any.

6. Material Balance: A rough material balance can be conducted (making sure the inputs equal the outputs), to determine if most of the input and output materials have been captured. Energy inputs will not be included in the material balance. 


\section{Brainstorming for: \\ Painting Pollution Prevention Opportunities}

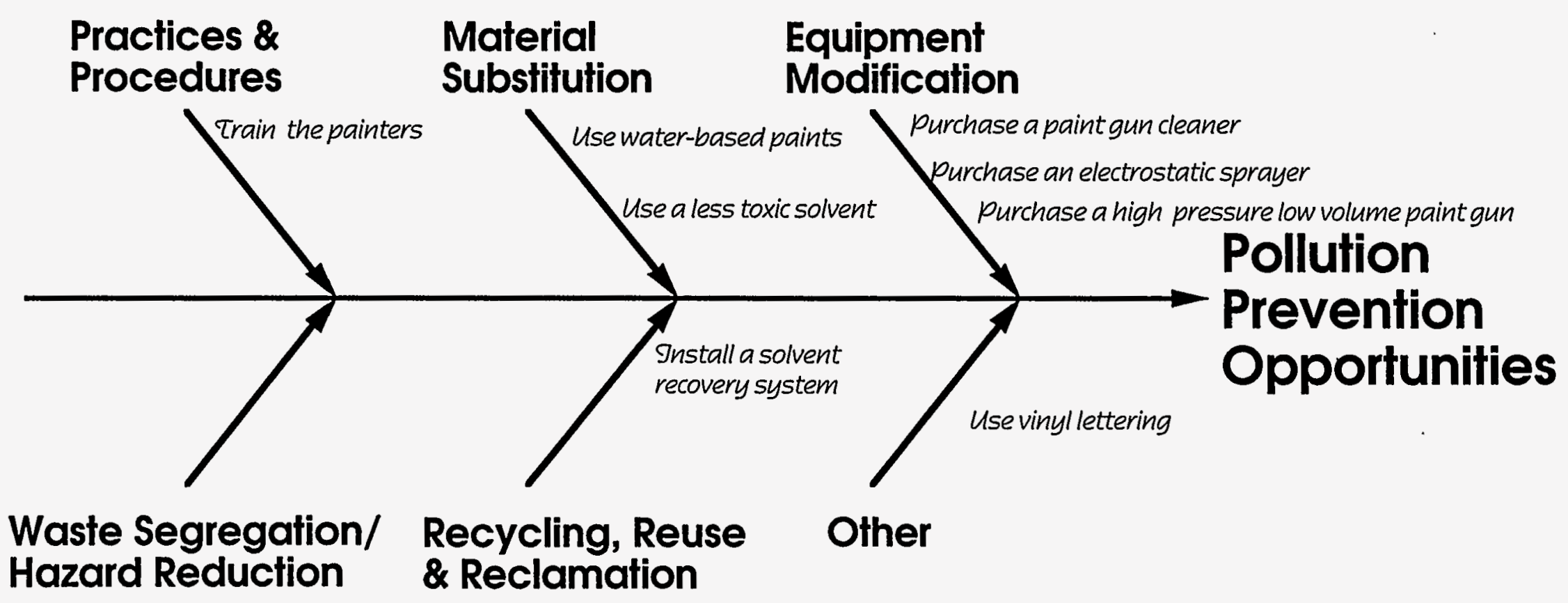




\section{Pollution Prevention Opportunity Assessment \\ WORKSHEET 3 \\ Pollution Prevention Opportunity Description}

Date: 418194

P2OA ID Code:

Solv-1

Facility: paintshop

Activity:

Spraypainting

P2O No. 1 P2O Title: SolventRecoverySystem

Current Practice: 100 drums ofspentsolventisshipped offsite as regulated waste.

Recommended Action: Purchase a solvent recovery system. The solvent recovery system should be able to handle 22 gallons of solvent per day with $90 \%$ efficiency. .

Calculation of Waste Reduction and/or Energy Savings: Anticipated reduction: disposal of 100 55-gallon drums: MEKperyear. Sludgefrom the solventrecovery system is still considered regulated waste and will beshipped offsite. Purchase of solventwill also be reduced, since an estimated half of the solventpurchased will be recycled.

Calculation of Annual Cost Savings: Looking at the purchase requisitions, itcosts $\$ 60$ a drum to purchase MEK. From thewastemanifest, disposal of thespentsolventis $\$ 175$ for a 55 gal.drum.

Savings = purchase savings + disposalsavings

Savings $=(50$ drums $\times \$ 60 /$ drum $)+(100$ drums $\times \$ 175 /$ drum $)=\$ 20,500$ lyear

Calculation of Implementation Cost and Payback: Upon discussion with 3 vendors, the average cost of a solvent recovery system was $\$ 13.900$ including procurement costs. Thus, payback is $\$ 13,900 \div \$ 20,500 / \mathrm{yr}=0.7$ yrs (8 months). 


\section{Guidelines for Worksheet 3}

Before these summary sheets can be completed, the team should hold a brainstorming session to develop Pollution Prevention Opportunities (P2Os). Brainstorming sessions are effective ways for individuals to generate options and should occur in an environment that encourages creativity and independent thinking. A knowledge of the activity is essential before the brainstorming session. Provided below is a fishbone diagram that may help the team generate ideas.

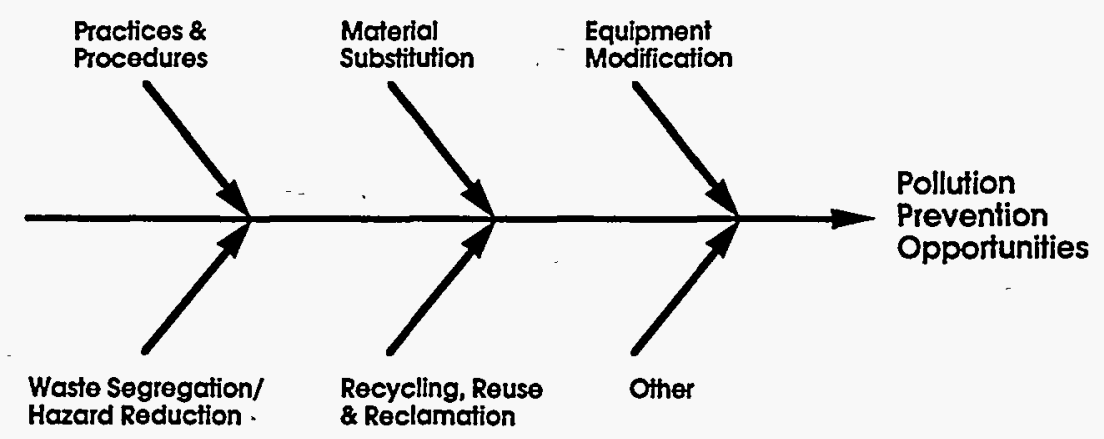

Promising P2Os from the brainstorming session should then be researched by individual teams members. This is in order to determine specifics related to the P2Os, and may involve calls to vendors or procurement, discussions with engineers, talking to line personnel and others. Considerable calculations and notes will most likely be taken on other sheets during the process. When complete, each idea's information can then be recorded on this summary sheet, which serves as a method to record and evaluate the options that have been identified.

1. Date, P2OA ID Code, Facility, Activity: List the date this sheet is completed, the unique P2OA ID code, facility, and the examined activity for this P2OA from Worksheet 1.

2. $\quad P 2 O$ No. and P2O Title: A number should be assigned to each $\mathrm{P} 2 \mathrm{O}$ from the complete brainstorm list and written here. The title should be descriptive of the recommendation, starting with an action verb (e.g, replace, modify, install, insulate, develop, reduce, retrofit, educate).

3. Current Practice: Briefly describe the current practice as it relates to this opportunity, so that the action described next can be fully understood.

4. Recommended Action: Describe what the change will be and how it will reduce waste or save energy.

5. Calculation of Waste Reduction and/or Energy Savings: Briefly describe the methodology used to determine waste and energy reductions. Cite references. List calculations as necessary to provide specific numbers. Be specific as to what the waste reduced consists of and what waste type is reduced (LLW, Mixed, Haz).

6. Calculation of Annual Cost Savings: Briefly describe the methodology used to determine cost savings. Cite references. List calculations as necessary to provide specific numbers. State the specific estimated costs savings for one year after implementation is complete.

7. Calculation of Annual Cost Savings \& Payback: Briefly describe the methodology used to determine implementation costs. Cite references. List calculations as necessary to provide specific values. Calculated payback as: implementation cost divided by annual savings. 


\section{Pollution Prevention Opportunity Assessment WORKSHEET 3 Pollution Prevention Opportunity Description}

Date: $4 / 8 / 94$ P2OA ID Code: Solv-1 Facility: paintshon

Activity: ___ Spraypainting

P2O No. 2 P2O Title: Use water-based paints

Current Practice: Useoil-basedpaintfor allpaintprocesses. 3 drums of MEK are usedperyear forpainting indoorsigns.

Recommended Action: Substitutenon-hazardouswater-basedpaints on all indoorsigns.

Calculation of Waste Reduction and/or Energy Savings: Anticipatedreduction: the purchase of 3 drums MEKperyear. Thewater-based paintwill notneed solventas a thinner and clean-upcan be accomplished with water. Also, from conversationswith painters, halfof MEKpurchased is disposed aswaste. TheotherhalfofMEKis released as air emissions.

Calculation of Annual Cost Savings: Looking at the purchase requisitions, itcosts $\$ 60$ for a 55 gal drum of MEK. Oil-based paintis $\$ 10.85$ Igallon. Water-based paintis $\$ 8.481$ gallon. From the manifest, disposal of thespentsolvent is \$175fora55 gal drum.

Savings = purchased solventsavings + disposal savings + productsubstitution savings.

Savings $=$ (3 drums $\times \$ 601$ drum $)+(\$ 175 /$ drum $\times 1.5$ drums $)+[(\$ 10.85-\$ 8.48) / \mathrm{gal} * 3$ drums $\times 55$ gall drum]

Calculation of Implementation Cost and Payback:

Water-based paintwill besubstituted as oil-based paint is used up. Therefore there is no implementation cost. Paybackisimmediate. 


\section{Guidelines for Worksheet 3}

Before these summary sheets can be completed, the team should hold a brainstorming session to develop Pollution Prevention Opportunities (P2Os). Brainstorming sessions are effective ways for individuals to generate options and should occur in an environment that encourages creativity and independent thinking. A knowledge of the activity is essential before the brainstorming session. Provided below is a fishbone diagram that may help the team generate ideas.

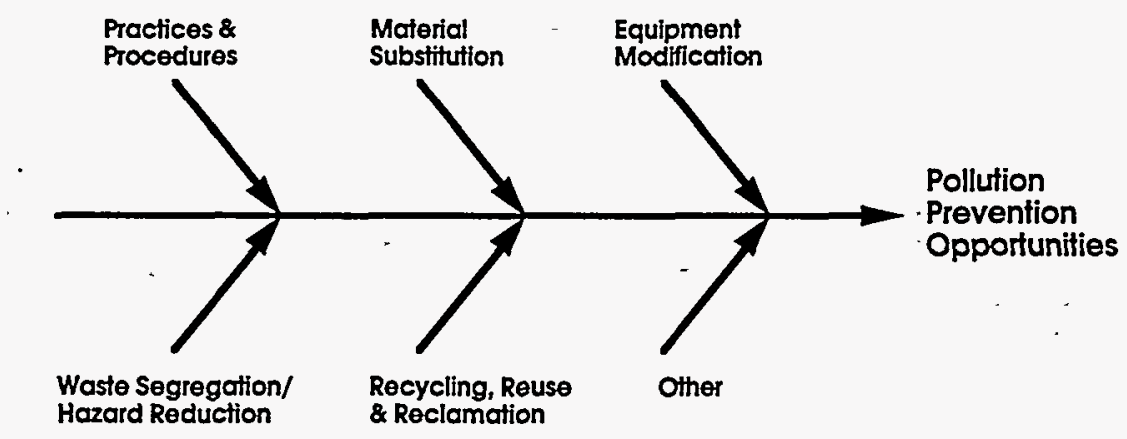

Promising P2Os from the brainstorming session should then be researched by individual teams members. This is in order to determine specifics related to thę P2Os, and may involve calls to vendors or procurement, discussions with engineers, talking to line personnel and others. Considerable calculations and notes will most likely be taken on other sheets during the process. When complete, each idea's information can then be recorded on this summary sheet, which serves as a method to record and evaluate the options that have been identified.

1. Date, P2OA ID Code, Facility, Activity: List the date this sheet is completed, the unique P2OA ID code, facility; and the examined activity for this P2OA from Worksheet 1.

2. $\quad \mathrm{P} 2 \mathrm{O}$ No and P2O Title: A number should be assigned to each $\mathrm{P} 2 \mathrm{O}$ from the complete brainstorm list and written here. The title should be descriptive of the recommendation, starting with an action verb (e.g, replace, modify, install, insulate, develop, reduce, retrofit, educate).

3. Current Practice: Briefly describe the current practice as it relates to this opportunity, so that the action described next can be fully understood.

4. Recommended Action: Describe what the change will be and how it will reduce waste or save energy.

5. Calculation of Waste Reduction and/or Energy Savings: Briefly describe the methodology used to determine waste and energy reductions. Cite references. List calculations as necessary to provide specific numbers. Be specific as to what the waste reduced consists of and what waste type is reduced (LLW, Mixed, Haz).

6. Calculation of Annual Cost Savings: Briefly describe the methodology used to determine cost savings. Cite references. List calculations as necessary to provide specific numbers. State the specific estimated costs savings for one year after implementation is complete.

7. Calculation of Annual Cost Savings \& Payback: Briefly describe the methodology used to determine implementation costs. Cite references. List calculations as necessary to provide specific values. Calculated payback as: implementation cost divided by annual savings. 


\section{Pollution Prevention Opportunity Assessment WORKSHEET 3 Pollution Prevention Opportunity Description}

Date: $418 / 94$ P2OA ID Code: Solv-1

Facility: paintshop

Activity: Spraypainting

$\mathrm{P} 2 \mathrm{ONo} 3$ P2O Title:_VinulLettering

Current Practice: Stencil letteringonsigns andequipmentwithoil-based paint. 1 drumof $M E K$ is used each year (preparing, stenciling and cleaning) in thestenciling process.

Recommended Action: Purchaseavinylletteringsystem. Thelettersarecutwithavinyl cuttingmachine and applied by hand.

Calculation of Waste Reduction and/or Energy Savings: Anticipatedreduction: purchase 1 drum of solventperyear. Also, halfdrums will notneed disposal (theother halfbeing airemissions).

Calculation of Annual Cost Savings: Lookingatpurchaserequisitions, itcosts $\$ 60$ to purchase MEK. Solventdisposal is $\$ 175$ perdrum. Although 25 gallons of paint will not have to bepurchased, the costof thelettering offsets this reduction.

Savings = disposal savings + purchasesavings

Savings $=($ half drum $\times \$ 175 /$ drum $)+(1$ drum $\times \$ 60 /$ drum $)=\$ 150$

Calculation of Implementation Cost and Payback: Themostappropriatepieceofequipment identified to meetourneedswas $\$ 6,000$. Thepaybackis $\$ 6,0001 \$ 150=40 \mathrm{yrs}$ 


\section{Guidelines for Worksheet 3}

Before these summary sheets can be completed, the team should hold a brainstorming session to develop Pollution Prevention Opportunities (P2Os). Brainstorming sessions are effective ways for individuals to generate options and should occur in an environment that encourages creativity and independent thinking. A knowledge of the activity is essential before the brainstorming session. Provided below is a fishbone diagram that may help the team generate ideas.

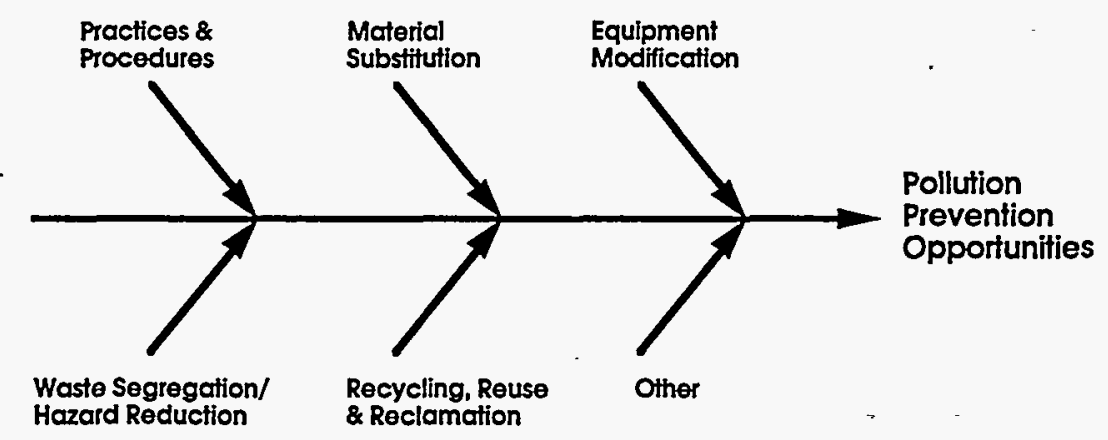

Promising P2Os from the brainstorming session should then be researched by individual teams members. This is in order to determine specifics related to the P2Os, and may involve calls to vendors or procurement, discussions with engineers, talking to line personnel and others. Considerable calculations and notes will most likely be taken on other sheets during the process. When complete, each idea's information can then be recorded on this summary sheet, which serves as a method to record and evaluate the options that have been identified.

1. Date, P2OA ID Code, Facility, Activity: List the date this sheet is completed, the unique P2OA ID code, facility, and the examined activity for this P2OA from Worksheet 1.

2. P2O No. and P2O Title: A number should be assigned to each $\mathrm{P} 2 \mathrm{O}$ from the complete brainstorm list and written here. The title should be descriptive of the recommendation, starting with an action verb (e.g, replace, modify, install, insulate, develop, reduce, retrofit, educate).

3. Current Practice: Briefly describe the current practice as it relates to this opportunity, so that the action described next can be fully understood.

4. Recommended Action: Describe what the change will be and how it will reduce waste or save energy.

5. Calculation of Waste Reduction and/or Energy Savings: Briefly describe the methodology used to determine waste and energy reductions. Cite references. List calculations as necessary to provide specific numbers. Be specific as to what the waste reduced consists of and what waste type is reduced (LLW, Mixed, Haz).

6. Calculation of Annual Cost Savings: Briefly describe the methodology used to determine cost savings: Cite references. List calculations as necessary to provide specific numbers. State the specific estimated costs savings for one year after implementation is complete.

7. Calculation of Annual Cost Savings \& Payback: Briefly describe the methodology used to determine implementation costs. Cite references. List calculations as necessary to provide specific values. Calculated payback as: implementation cost divided by annual savings. 


\section{Pollution Prevention Opportunity Assessment WORKSHEET 4 Pollution Prevention Opportunities Summary}

Date: $4 / 8 / 94$

P2OA ID Code: Solv-1

Facility:_paintshop

Activity:

Spraypainting

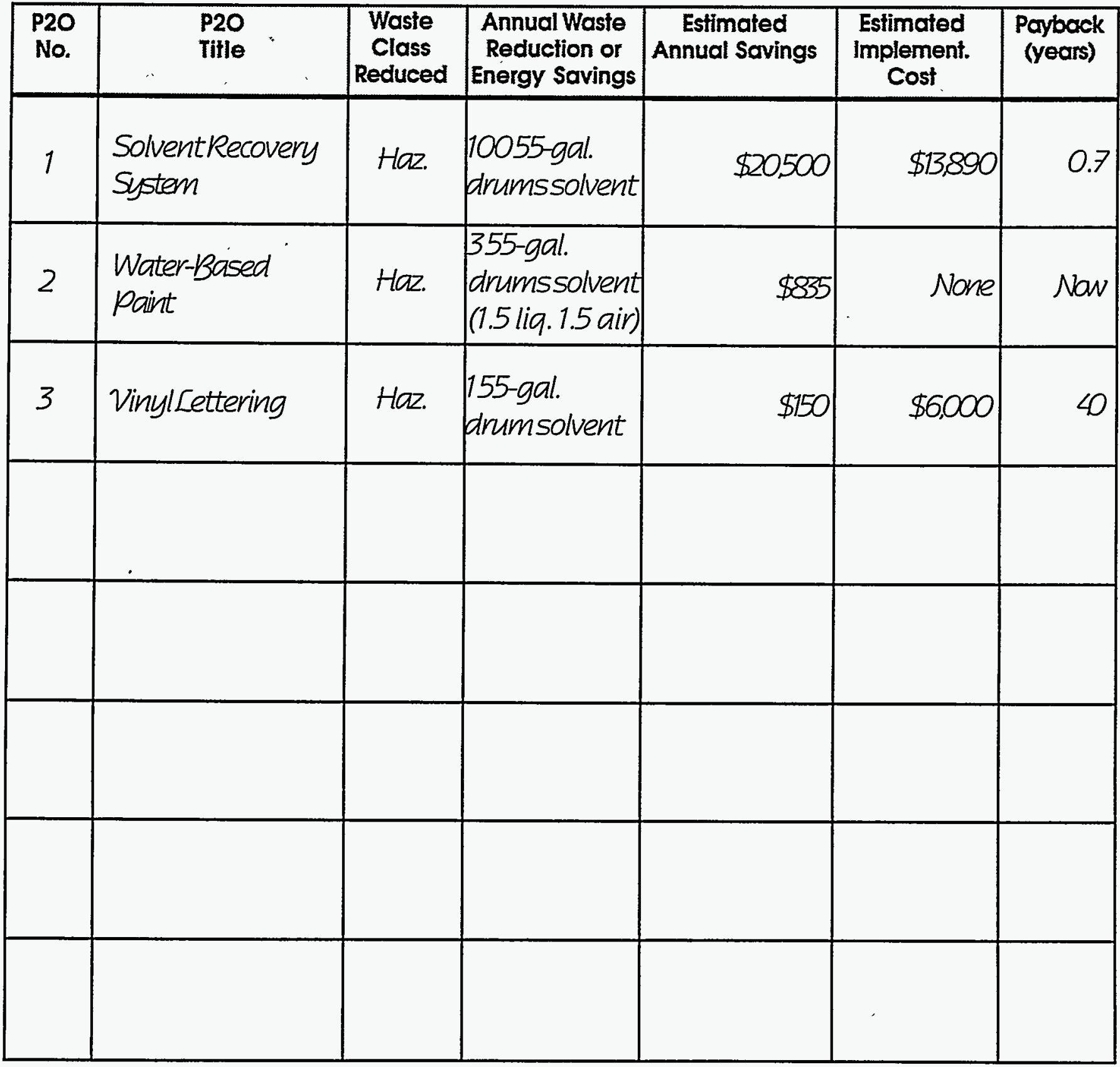

Notes and Other Benefits: 


\section{Guidelines for Worksheet 4}

This worksheet is meant as a simple way to compare the P2Os with each other after the research and feasibility analysis has been completed. They can be listed according to the P2 hierarchy (source reduction first, followed by recycling/reuse, and treatment). They can also be listed according to the shortest payback, either within each hierarchy level or overall.

1. Date, P2OA ID Code, Facility, Activity: List the date this sheet is completed, the unique P2OA ID code, facility, and the examined activity for this P2OA from Worksheet 1 .

2. P2O No., Title, Waste Class, Reduction, Savings, Implementation, and Payback: These values can all be entered directly from the sections in Worksheets 3 . If a savings or a implementation cost is very small, write 'negligible.' Just because an idea is not cost-effective or a large waste reducer, does not mean it should not be listed-it may be a simple"low-hanging fruit" that can be accomplished giving instant success or good public relations. Some ideas may ease compliance with regulations, or resolve a safety concern and thus should be considered also.

3. Notes and Other Benefits: The notes section can include any regulatory drivers for a particular P2O or other important issues besides cost or P2 hierarchy to be considered. 


\section{Pollution Prevention Opportunity Assessment \\ WORKSHEET 5 \\ Final Summary}

Date: $4 / 8194$

P2OA ID Code:

Solv-1

Facility:_paintshop

Activity: Spraypainting

Proposed Opportunities and Discussion: The solventrecovery system has significantcost savings associated with the purchase of new equipment. Eliminating the spentsolventwill reduce waste disposal costs. Using non-hazardouswater-based paints willsave in disposal costs and in productpurchase costs. Applyingvinulletteringon indoorsigns reduces worker exposure, butthe payback is notsufficient to purchase the equipmentnecessary.

Recommendations \& Schedule for Implementation: Implement the solvent recovery system immediately. In addition, non-toxic paint should always be used for indoor signs. It is not recommended to purchase a vinyl lettering system as the payback is not sufficient. 


\section{Guidelines for Worksheet 5}

This sheet provides a brief summary about the whole assessment. Its purpose is to document how this assessment was performed, the conclusions reached by the team, and the recommendations for further actions. For a more complex assessment, a longer, more formal executive summary may want to be written out for presentation to management.

1. Date, P2OA ID Code, Facility, Activity: List the date this sheet is completed, the unique P2OA ID code, facility, and the examined activity for this P2OA from Worksheet 1.

2. Proposed Opportunities and Discussion: Briefly describe the main opportunities examined, including the waste streams or input material to be minimized, benefits achieved, and any positive and negative aspects to the opportunities.

3. Recommendations \& Schedule for Implementation: Briefly describe any actions that should or will be taken in respect to this assessment. Provide a recommendation for date of implementation. 
Appendix C: P2 Group Contacts and other Hanford Numbers

This Appendix contains a contact list for Pollution Prevention and other help numbers at the Hanford Site.

\section{Pollution Prevention Hotline} $376-6239$

\section{Pollution Prevention Group}

Each member of the P2 Group has several facilities assigned to them with which they are familiar (these are in (S). Feel free to call or send electronic mail to your primary contact, or any member.

Mary Betsch (FMEF, FFTF, ICF KH) ........................... 372-1627

Jill Engel (222-S, 2703E, BHI) ..................................... 376-8737

Ben Floyd (Solid Waste, Geotech, B-Plant) .............376-8467

Craig Joseph (340, 200 Eff Treat, TEDF, PUREX/UO3) $372-1375$

Donna Merry (PFP, HEHF, PNL) .................................. 376-9773

Dave Nichols (IRM, Chem Process Eng, K-Basins, Patrol, TWRS) 376-4351

Liz Raney (T-Plant, Engineering-305\&306E, Fire Dept)

$372-9294$

\section{Recycling/Procurement Control}

Kim McDowell

\section{Chemical Exchange}

Jerry Brown

$376-7122$

Facility Design Guidelines

Liz Raney

$372-9294$

Solid Waste Information Tracking System (SWITS) Information Darlene Hagel 373-0355

Hazardous Material Inventory Database (HMID2) Information Lorna Dittmer $376-8478$

P2Info (voice), managed by Pacific Northwest Laboratory Information exchange 3P2-INFO (372-4636) 
Appendix D: Off-Site Help and References

This Appendix contains a contact list for pollution prevention help numbers and references off-Site.

DOE's Pollution Prevention Information Clearinghouse (EPIC) (computer access to all kinds of P2 information from many DOE sites and DOE-HQ)

For Voice information about EPIC (301) 208-6811

With modem (800) $821-4674$

Hanford Site Waste Minimization and Pollution Prevention Awareness Program Plan, DOE/RL-91-31, Rev. 1. United States Department of Energy, Richland, WA, May 1994. Available from the P2 Group, 376-6239, or the Office of Scientific and Technical Information, (615) 576-8401.

Model Pollution Prevention Opportunity Assessment Guidance. United States Department of Energy, Office of Defense Programs, Washington, D. C., December 1993. Available (plus, any other DOE P2OA guidance) from Susan Pemberton, Kansas City Plant, (816) 997-5435.

Waste Minimization/Pollution Prevention Crosscut Plan 1994, DOE/FM-0145. United States Department of Energy, Washington, D. C.. Available from the P2 Group, 376-6239, or the Office of Scientific and Technical Information, (615) 576-8401.

Annual Report on Waste Generation and Waste Minimization Progress 1991-1992, DOE/S-0105. United States Department of Energy, Washington, D. C., February 1994. Available from the P2. Group, 376-6239, or the Office of Scientific and Technical Information, (615) 576-8401.

The EPA Manual for Waste Minimization Opportunity Assessment, EPA/600/2-88-025. United States Environmental Protection Agency, Cincinnati, Ohio, April 1988. Available from Pollution Prevention Research Branch, Risk Reduction Engineering Laboratory, U.S. EPA, Cincinnati, Ohio 45268. They also have a number of research briefs on many P2OA projects.

The Facility Pollution Prevention Guide, EPA/600/R-92/088. United States Environmental Protection Agency, Cincinnati, Ohio, May 1992. Available from Pollution Prevention Research Branch, Risk Reduction Engineering Laboratory, U.S. EPA, Cincinnati, Ohio 45268. 